\title{
Seismic anisotropy inferred from direct $S$-wave-derived splitting measurements and its geodynamic implications beneath southeastern Tibetan Plateau
}

\author{
Ashwani Kant Tiwari ${ }^{1}$, Arun Singh ${ }^{1}$, Tuna Eken ${ }^{2}$, and Chandrani Singh ${ }^{1}$ \\ ${ }^{1}$ Department of Geology and Geophysics, Indian Institute of Technology Kharagpur, Kharagpur, India \\ ${ }^{2}$ Department of Geophysical Engineering, Istanbul Technical University, Istanbul, Turkey
}

Correspondence to: Arun Singh (arun@gg.iitkgp.ernet.in)

Received: 15 September 2016 - Revised: 20 September 2016 - Accepted: 4 February 2017 - Published: 7 April 2017

\begin{abstract}
The present study deals with detecting seismic anisotropy parameters beneath southeastern Tibet near Namcha Barwa Mountain using the splitting of direct $S$ waves. We employ the reference station technique to remove the effects of source-side anisotropy. Seismic anisotropy parameters, splitting time delays, and fast polarization directions are estimated through analyses of a total of 501 splitting measurements obtained from direct $S$ waves from 25 earthquakes ( $\geq 5.5$ magnitude) that were recorded at 42 stations of the Namcha Barwa seismic network. We observe a large variation in time delays ranging from 0.64 to $1.68 \mathrm{~s}$, but in most cases, it is more than $1 \mathrm{~s}$, which suggests a highly anisotropic lithospheric mantle in the region. A comparison between direct $S$ - and SKS-derived splitting parameters shows a close similarity, although some discrepancies exist where null or negligible anisotropy has been reported earlier using SKS. The seismic stations with hitherto null or negligible anisotropy are now supplemented with new measurements with clear anisotropic signatures. Our analyses indicate a sharp change in lateral variations of fast polarization directions (FPDs) from consistent SSWENE or W-E to NW-SE direction at the southeastern edge of Tibet. Comparison of the FPDs with Global Positioning System (GPS) measurements, absolute plate motion (APM) directions, and surface geological features indicates that the observed anisotropy and hence inferred deformation patterns are not only due to asthenospheric dynamics but are a combination of lithospheric deformation and sub-lithospheric (asthenospheric) mantle dynamics. Direct $S$-wave-based station-averaged splitting measurements with increased back-azimuths tend to fill the coverage gaps left in SKS measurements.
\end{abstract}

\section{Introduction}

The Tibetan Plateau has a long history of deformation within the last 50 million years (e.g. Rowley and Currie, 2006; Henderson et al., 2011). The reliability of seismic anisotropy measurements is a challenging issue as it is essential to identify the tectonics, coupling-decoupling of the crust-lithospheric mantle, multi-layered anisotropic modelling, and active seismicity in relation to the type of deformation and possible flow patterns, which are still a matter of debate in understanding the formation process and future challenges of this active region.

Lattice-preferred orientation (LPO) of olivine mineral in the mantle as a result of plate interactions is controlled by various geodynamic processes and is considered to be the main cause of the shear wave splitting observations on the teleseismic $S$ and SKS waves. Deformation in the upper mantle generally takes place through two processes: diffusion and dislocation creep under favourable conditions. The dislocation creep process, which is the creeping motion of crystal dislocation, is considered to be the leading cause of mantle anisotropy (Karato, 1987; Nicolas and Christensen, 1987; Karato and Wu, 1993; Mainprice et al., 2000). It can be caused by either high-stress conditions or large grain size or both, but the nonlinear increase in the strain rate is independent of the grain size (Karato and Wu, 1993). This type of deformation is expected to occur at a depth range of less than $400 \mathrm{~km}$ (e.g. Karato, 1984, 1987) where olivine is the most common mineral, and hence LPO development and observed anisotropy mainly represents the upper $400 \mathrm{~km}$ of the mantle (Becker and Faccenna, 2011). 
Several observations on seismic anisotropy have greatly contributed to elucidating these deformation patterns in relation to the past and present geodynamic activity of the region. Generally speaking, SKS splitting analyses are the most diagnostic, quick, and well-established way of detection and quantification of seismic anisotropy. The SKS phase does not propagate as an $S$ wave in the liquid outer core and refracts from a $P$ wave into an SV (radially polarized) wave when entering the receiver-side mantle. Hence a recorded SKS phase at the surface is not influenced by the source-side anisotropy. The main disadvantage of using the SKS phase in splitting measurements is that finding good-quality observations is restricted by several parameters, i.e. epicentral distance and propagation direction of the event, and therefore the measurements need to be supplemented with other phases (e.g. $\mathrm{ScS}$ and direct $S$ ) that can provide better azimuthal coverage. However, employing such additional phases may introduce contamination due to the source-side anisotropy. Splitting of shear waves is similar to the birefringence phenomena in optics. Shear waves split into fast and slow components when they pass through an anisotropic medium. In such a situation, we obtain particle motion (e.g. elliptical, cruciform) with different shapes that depend on the anisotropy along the ray path. If the anisotropy is the only cause of splitting, then the observed shear wave (fast or slow) can be rotated in such a way that two very similar phases are seen, apart from scaling and a time delay between them (Silver and Chan, 1991; Savage, 1999; Long and Silver, 2009). Resultant splitting parameters, $\phi$ and $\delta t$, indicate the rotation angle in relation to the flow direction and shearing or extension along the ray path under the assumption of LPO in the upper mantle (a.k.a. fast polarization direction or FPD), and to the strength and thickness of the anisotropic layer (a.k.a. delay time), respectively. Splitting measurements from the Himalaya-Tibet collision zone have long been explained by the presence of a single homogeneous layer with a horizontal axis of symmetry (e.g. McNamara et al., 1994; Chen et al., 2010; Sol et al., 2007; Herquel et al., 1995; Hirn et al., 1995; Lavé et al., 1996; Sandvol et al., 1997; Huang et al., 2000; Lev et al., 2006; Wang et al., 2008; Fu et al., 2008; Sato et al., 2012).

The use of direct $S$ waves of earthquakes at teleseismic distances $\left(30-90^{\circ}\right)$ can provide complementary splitting measurements to SKS measurements as this helps in establishing a more complete database of anisotropy that will be inferred from good-quality $S$ wave signals from an enhanced azimuthal distribution relative to SKS splitting only. This is crucial for the Indian subcontinent where SKS measurements are skewed towards eastern azimuths, and very few SKS measurements have been obtained due to temporary deployments (see Singh et al., 2015). However, the major problem in including direct $S$ waves in splitting measurements is the contamination of the $S$ wave signals due to the influence of anisotropic structures existing within the sourceside region. Eken and Tilmann (2014) have recently shown that this problem can be overcome using an array-based ap-

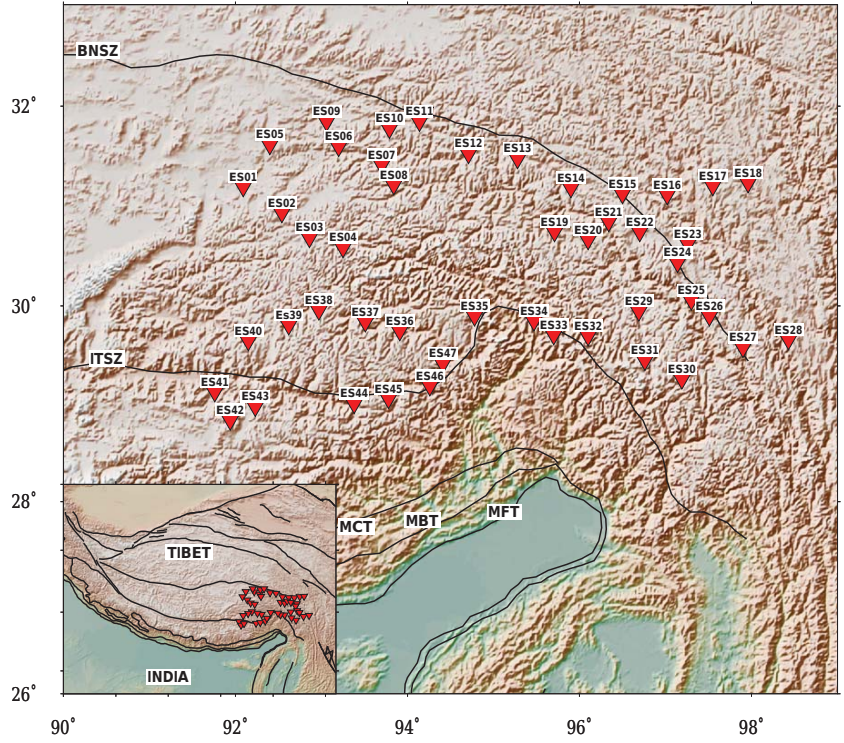

Figure 1. Tectonic and topographic map of the Himalayas and Tibet. Red triangles represent the broadband seismic stations of the XE network within the study region (MFT: Main Frontal Thrust; MBT: Main Boundary Thrust; MCT: Main Central Thrust; ITSZ: Indus-Tsangpo suture zone; BNSZ: Bangong-Nujiang suture zone).

proach, known as the reference station technique (RST). The method assumes an identical source-side anisotropy effect at two closely located stations (reference and target stations) with small differences in epicentral distances. In this case, optimum splitting parameters can be estimated by searching for receiver-side correction parameters for the target station that result in maximum similarity to the $S$ wave signal corrected for previously known receiver-side anisotropy beneath the reference station in a grid search scheme. Signals used for that comparison are those of the reference station previously corrected for known reference receiver-side anisotropy and of the target station whose receiver-side splitting parameters are desired to be estimated. In this technique, we utilize seismic anisotropy parameters, which were previously inferred from the SKS measurements by Sol et al. (2007) as the reference knowledge of the receiver-side anisotropy beneath the reference station. The RST has been successfully tested through both synthetic and observed data collected along the northeastern and southwestern parts of the Tibetan Plateau and the Hellenic Trench in the eastern Mediterranean (e.g. Eken and Tilmann, 2014; Singh et al., 2016; Confal et al., 2016). The present study focuses on the southeastern part of Tibet near Namcha Barwa (Fig. 1). The study region is located between and around the Indus-Tsangpo suture zone (ITSZ) and Bangong-Nuijiang suture zone (BNSZ). Our major motivation is to calculate $S$-wave-derived seismic anisotropic parameters that may have a potential link to tectonic setting and deformation history with the help of a 


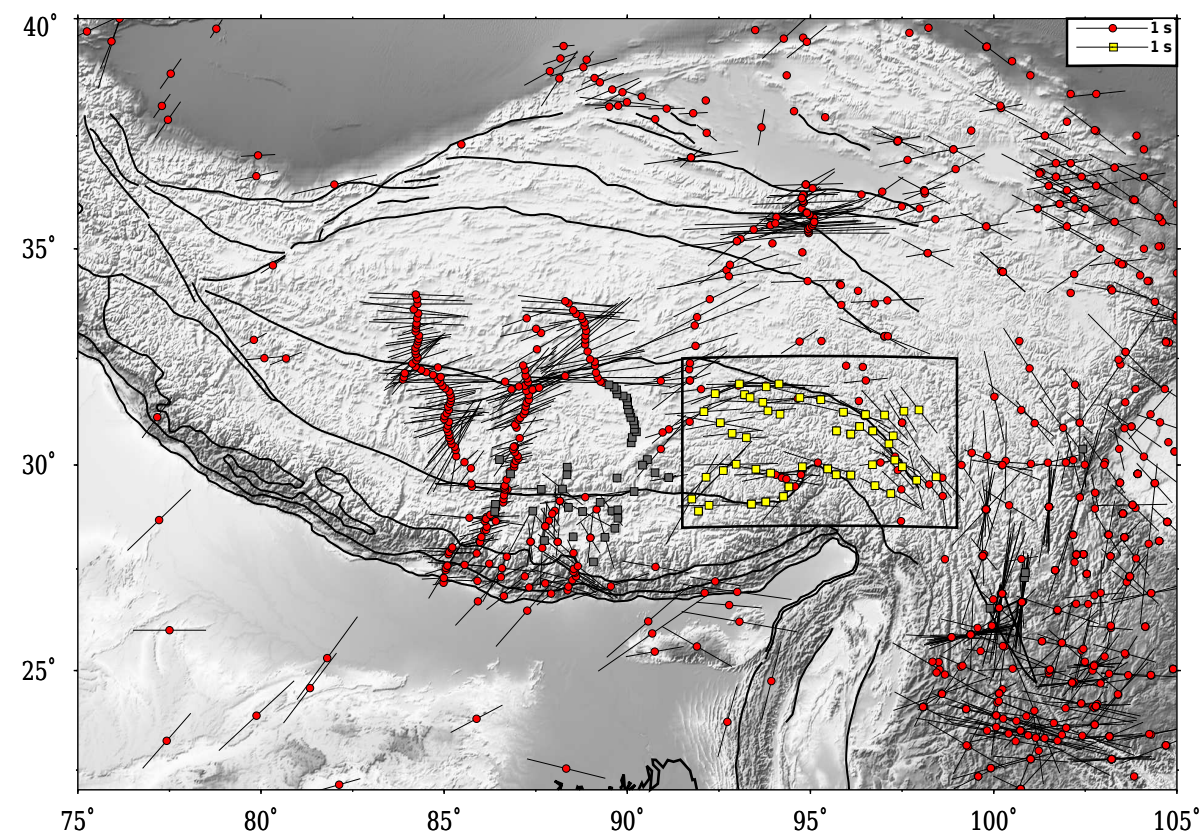

Figure 2. Earlier SKS and SKKS measurements in the study area (Sol et al., 2007; Wüstefeld et al., 2008). The length of solid bars shown for each seismic station is proportional to the splitting time delay $\left(\delta t_{\mathrm{S}}\right)$, and their orientation represents the fast polarization direction $\left(\phi_{\mathrm{S}}\right)$. For clarity, the seismic stations used in the present study are shown by yellow-filled rectangles along with the SKS splitting measurements of Sol et al. (2007). Seismic stations where null or negligible anisotropy is reported in earlier studies (see Wüstefeld et al., 2008) are shown by grey-filled rectangles. All other stations are shown by red-filled circles.

correlative analysis of resultant anisotropy observations with absolute plate motion (APM) directions, GPS measurements, and the structural and topographic features. Our results contradict previous interpretations of an isotropic Indian lithospheric mantle (Chen and Ozalaybey, 1998; Barruol and Hoffmann, 1999; Chen et al., 2010) and add new constraints in understanding the types of deformation and their causes in the region.

\section{Tectonics of the region}

The formation of the Tibetan Plateau and the Himalayan mountain belt is due to collision and post-collision processes of the Indian and Eurasian plates starting at around $50 \mathrm{Ma}$ (Argand, 1924; Garzanti and Van Haver, 1988; Molnar and Tapponnier, 1975; Yin and Harrison, 2000; Royden et al., 2008). Underthrusting of the Indian lithosphere beneath the Eurasian lithosphere has been proposed to be the main reason for the formation of the Himalayan and Karakorum ranges (Nelson et al., 1996; Kumar et al., 2006; Tseng et al., 2009) along with the formation of the central Tibetan region (Argand, 1924; Nelson et al., 1996; Li et al., 2008). The underlying reason for the development of the northern and eastern Tibetan Plateau, however, remains enigmatic (Karplus et al., 2011; Royden et al., 2008). McKenzie and Priestley (2008) discuss the development of the northern Tibetan lithosphere as an accreted one. Royden et al. (2008) argue that the Ti- betan Plateau evolved due to the subduction of the Indian lithosphere beneath Eurasia, which is also responsible for the thickening of the Tibetan crust and afterwards the extrusion of the Tibetan lithosphere towards the east.

Various models have been developed regarding the deformation of Tibet (Royden et al., 1997; Molnar and Tapponnier, 1975; Houseman and England, 1986, 1993, 1996; Tapponnier et al., 1982, 2001; Shen et al., 2001; Holt et al., 1995, 2000; Replumaz and Tapponnier, 2003; Flesch et al., 2001), but no single model can explain all of it. The debate regarding the crust and mantle deformation patterns and ongoing geodynamics has not been settled. Recent work by Jagoutz et al. (2015) and Van Hinsbergen et al. (2012) suggests a model involving multistage subduction of the Tethys oceanic plate and the Indian Plate below the Eurasian Plate resulting in a highly heterogeneous and anisotropic lithosphere. The Tibetan and Himalayan region is mainly dominated by thrust and strike-slip faulting. Suture zones are extended in the E-W direction and take a sharp turn around the eastern Himalayan syntaxis (EHS; Fig. 1). Strike-slip faulting becomes more dominant to the east of the EHS. Figure 1 shows that the eastern portion of the subducting Indian Plate is found adjacent to the EHS (León Soto et al., 2012) where the structural and topographical features take a sharp trend from nearly W-E striking to $\mathrm{N}-\mathrm{S}$ striking. 

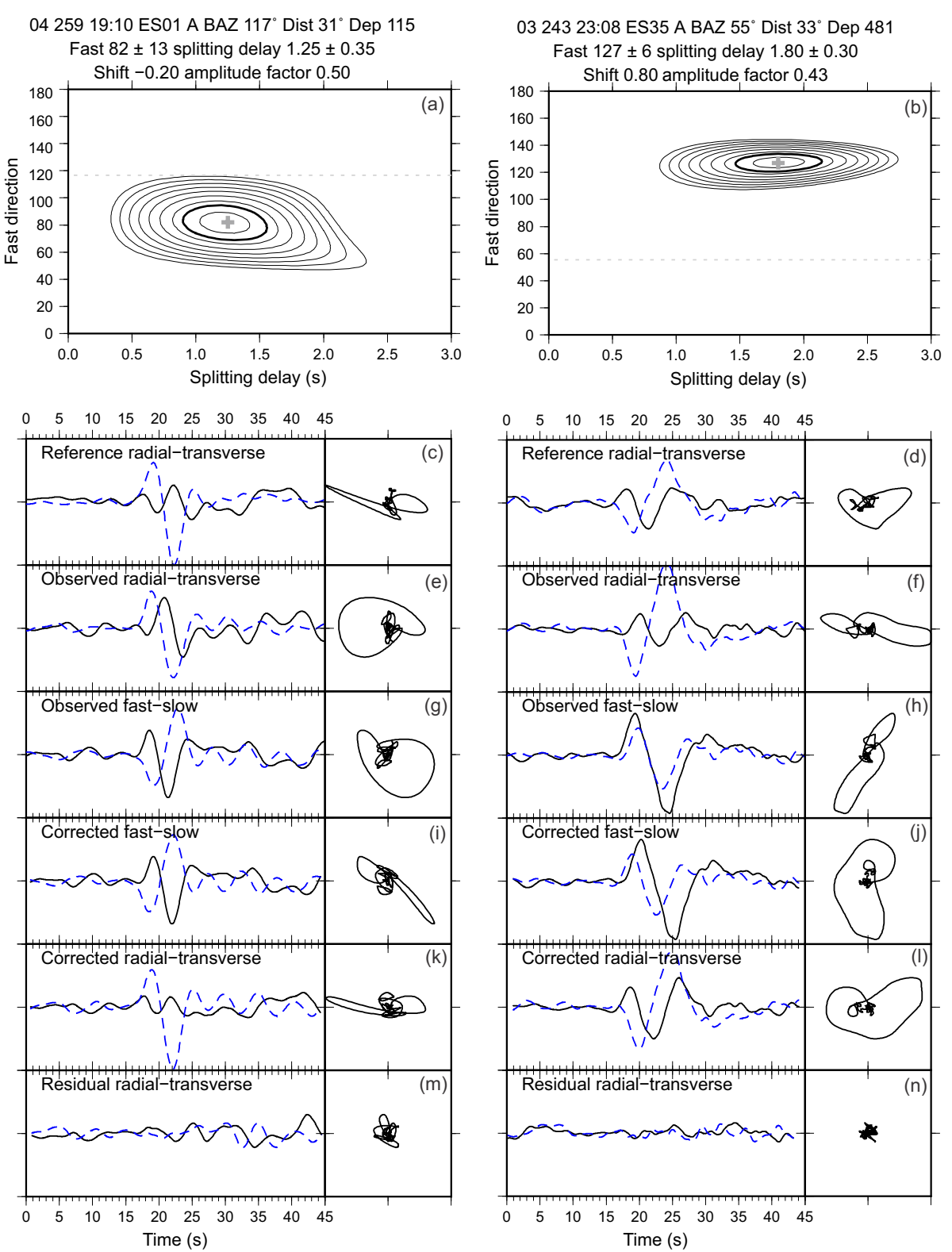

Figure 3. Examples of the direct $S$ wave splitting measurements based on the reference station technique at stations ES01 and ES35. Figures on the left side represent the splitting measurement recorded at station pair ES03 (reference station)-ES01 (target station), and those on the right side represent the splitting measurement recorded at station pair ES16 (reference station)-ES35 (target station). (a) Misfit surface with splitting parameter $82^{\circ} \pm 13^{\circ}$ and $1.25 \pm 0.35 \mathrm{~s}$. (c) Signal at reference station (ES03) with receiver-side correction. (e) Signal at target station (ES01). (g) Fast and slow component after rotating signal at target station (ES01) using $\phi\left(82^{\circ}\right)$. (i) Fast and slow component corrected for $\delta t(1.25 \mathrm{~s})$. (k) Corrected radial and transverse components at target station (ES01) using optimum $\phi$ and $\delta t$ and isotropic delay ( $-0.2 \mathrm{~s}$ ). (m) Residual trace. Panels on the right side follow the same order and explanation.

\section{Data and method}

In this study, we examine a total of 5285 waveforms with the direct $S$ waves extracted from 161 teleseismic events with magnitudes $\geq 5.5$ within an epicentral distance range from 30 to $90^{\circ}$. The teleseismic events used in this study are recorded at 47 seismic stations of the XE network, which operated between 2003 and 2004 (Sol et al., 2007). Of those
47 stations, we selected for use as reference stations only those 36 seismic stations where we have knowledge of seismic anisotropy inferred from SKS splitting measurements performed by Sol et al. (2007). Prior to the data analysis, we remove the instrument response from the original seismograms to overcome biases that can depend on the potential use of different stations (at reference and target sites). At the stage of the preprocessing, a band-pass filter between 
0.03 and $0.2 \mathrm{~Hz}$ is performed to enhance $S$ signals and resample the seismograms at 20 samples per second to avoid aliased signals and to reconstruct the waveforms in the appropriate frequency range. Signals with possible contamination with other phases, such as ScS, SKKS, and SKS, are omitted from the analysis. We select only those waveforms, which have $\geq 2.5$ signal-to-noise ratio (SNR) on the transverse and radial components for further analysis. The selection of the waveforms is achieved by performing a manual visual inspection that allowed only $40 \%$ of the direct $S$ waveforms. We begin data analysis by determining station pairs over the entire area. We form the station pairs by selecting the same earthquake event recorded at both (reference and target) stations. Eken and Tilmann (2014) and Singh et al. (2016) successfully applied the RST to regional arrays with an interstation distance less than $300 \mathrm{~km}$. By taking $300 \mathrm{~km}$ interstation spacing as the limit in a similar fashion, we have formed 22816 station pairs with four horizontal components available at reference and target stations out of 35649 possible station pairs; these are based on 161 teleseismic events prior to the application of the technique. To minimize the effects of the coda waves and converted phases, we use a $45 \mathrm{~s}$ time window starting $15 \mathrm{~s}$ before the theoretical onset of the direct $S$ waves on the basis of the IASP91 1-D radial earth velocity model of Kennett (1991). This excludes the undesired effect of crustal $S$ multiples in the thick Tibetan crust.

The approach used in the present study avoids the sourceside anisotropy by minimizing the misfit function between the corrected seismic waveforms at the reference and target stations. At the first stage, an inverse splitting operator depending on a backward angular rotation with two horizontal components, a time shift, and the reversal of the back angular rotation are employed to correct the reference station for known receiver-side anisotropy (generally inferred from SKS splitting analyses) when estimating the direct- $S$-derived individual splitting parameter (Eken and Tilmann, 2014). Following the correction of the reference station, $S$ signals are corrected for splitting parameters in a grid search manner at the target stations. Corrected $S$ wave signals at reference and target stations are compared to each other for each pair of splitting parameters. Such comparison also allows for time shifts and amplitude corrections to account for the lateral heterogeneities and differences in site response between these stations by optimizing the time shift $(\Delta t)$ and amplitude factor $(a)$. First, we assign splitting parameters that minimized the misfit function simply representing the difference between the corrected reference and target station traces as optimum splitting parameters for the receiver-side beneath the target station at a given station pair. Later, taking the average of all optimum splitting parameters estimated at station pairs related to a given target station are considered representative of a given event. In the end, station-pair averaged splitting parameters are averaged over all events to estimate the final splitting parameters at each given target station.
Here we should note that our approach initially depends on the knowledge of receiver-side seismic anisotropy that can be most likely inferred from directionally averaged SKS splitting parameters at a given reference station. Conventional SKS splitting measurements are performed under the assumption of a single-layer anisotropic structure with a horizontal axis of symmetry. However, beneath the regions with complex anisotropic structures, for instance, in the case of a well-developed continental lithosphere with a dipping axis of symmetry (i.e. stable cratonic regions, see Plomerová et al., 2008) or an existing double-layer anisotropy (Silver and Savage, 1994), significant directional variation of apparent splitting parameters will likely be expected. In such regions, the average value of splitting parameters as reference knowledge of seismic anisotropy cannot be representative of the events from different directions, thus making resultant average $S$ derived splitting parameters misleading in our method since complicated anisotropic structures likely introduce a similar influence on both the SKS phase and direct $S$ waves. However due to the fact that our approach certainly provides more splitting observations from an increased amount of back-azimuths, these new directionally enhanced apparent $S$-derived splitting parameters help in resolving the actual orientation of the anisotropic structure by using more sophisticated modelling strategies, which is not within the scope of the present work.

The RST relies on two important underlying assumptions: (i) the ray path at two stations can be considered equivalent in the deeper mantle part and near the source-side region due to the fact that the distance between receiver and target stations is small $(<300 \mathrm{~km})$ compared to the epicentral distance; (ii) waveform differences between the receiver and target stations are only due to differences in anisotropic structure after correcting any waveform differences in time and amplitude presumably due to the lateral heterogeneities and differences in site response between these stations. Any potential difference between the thickness of the crust and sedimentary layers will also cause the timing and amplitude of converted phase, but Eken and Tilmann (2014) showed, numerically, its influence on expected splitting parameters would be negligible. During the application of the technique, we let $\phi$ and $\delta t$ vary from 0 to $180^{\circ}$ with an increment of $1^{\circ}$ and from 0 to $3 \mathrm{~s}$ with an increment of $0.05 \mathrm{~s}$, respectively. We perform an inverse $F$ test error analysis for uncertainty estimates of obtained splitting parameters. In this process, we check the reliability of the individual splitting parameters by comparing variation in the residual energy distribution away from the minimum with the variation according to the preset confidence level of $95 \%$. At this stage, the number of degrees of freedom in the data and unknown model parameters becomes crucial. According to Silver and Chan (1991) 1 degree of freedom is set to $1 \mathrm{~s}$ and considering two horizontal components, the number of degrees of freedom becomes 2 times the data length, which could be considered a typical value for teleseismic data. In our case, however, the number 

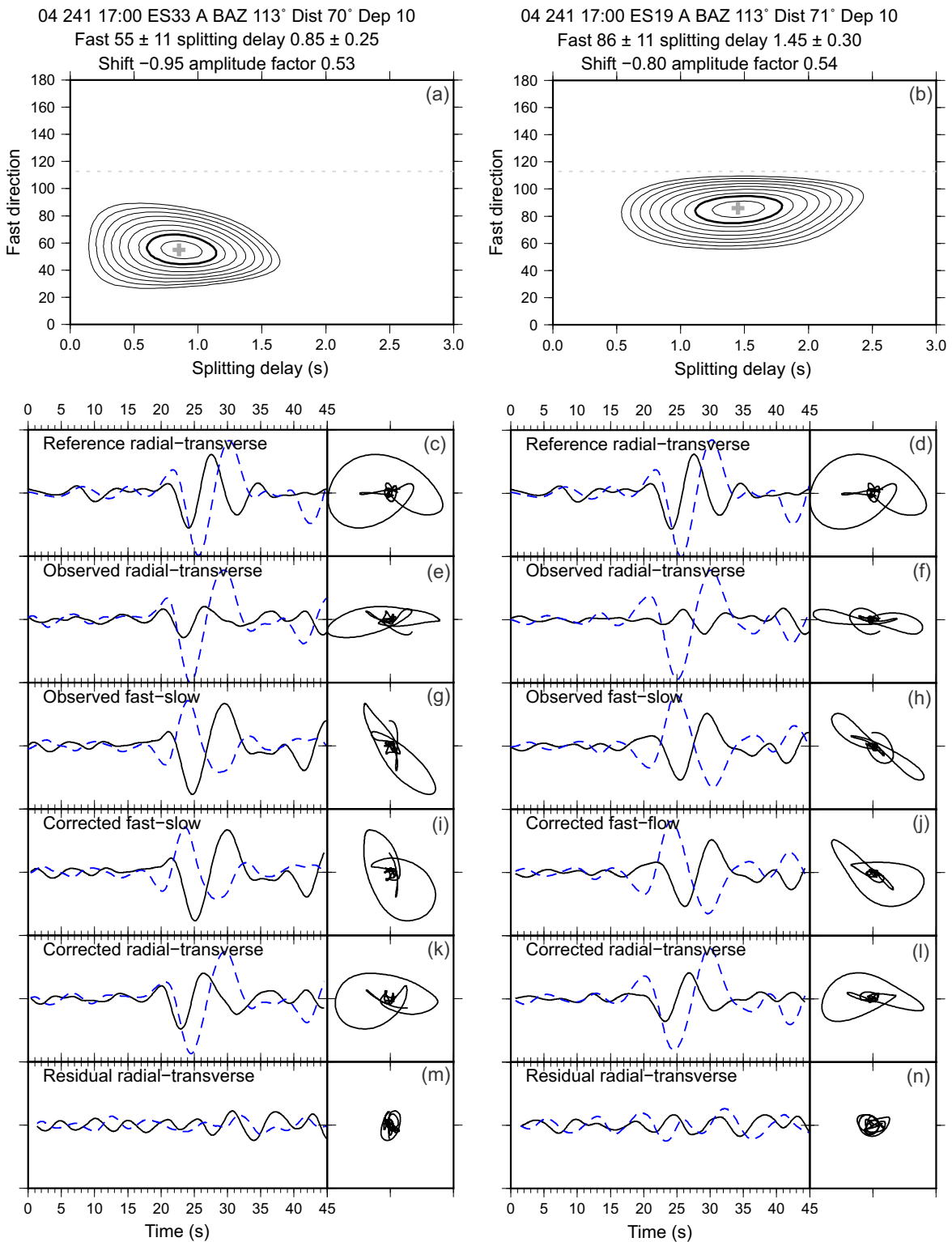

Figure 4. Examples of the direct $S$ wave splitting measurements based on the reference station technique at stations ES33 and ES19, where previously null anisotropy was obtained using an SKS splitting measurement (Sol et al., 2007). Panels on the left side represent the splitting measurement observed at the station pair with ES12 (reference station) and ES33 (target station), and those on the right side represent the splitting measurement observed at the station pair with ES12 (reference station) and ES19 (target station). The explanation for each panel is the same as in Fig. 3.

of unknown model parameters is four at the minimum point ( $\phi$ and $\delta t$, isotropic delay, amplitude correction factor) or two at any given splitting parameters tried in the grid search, reducing the number of degrees of freedom by four or two, respectively. Estimating the number of degrees of freedom is a challenging task. For an appropriate uncertainty analysis, the assumption of band-limited Gaussian noise is required to be justified as reported by Walsh et al. (2013). Thus, taking a fixed value for the degrees of freedom as performed in this study will allow us to compare the reliability of different in- dividual splitting estimates rather than the absolute value of the error bounds.

An example of the basic steps of the RST can be found in Fig. 3 for target stations ES01 and ES35, respectively. Figure 4 present the examples of the obtained splitting parameters at target stations ES19 and ES33, where null or no measurements are reported by Sol et al. (2007). Null splitting may be observed for three reasons: (i) if the incoming polarization direction below an anisotropic layer is parallel to the fast or slow axis; (ii) if the region is isotropic in nature due 

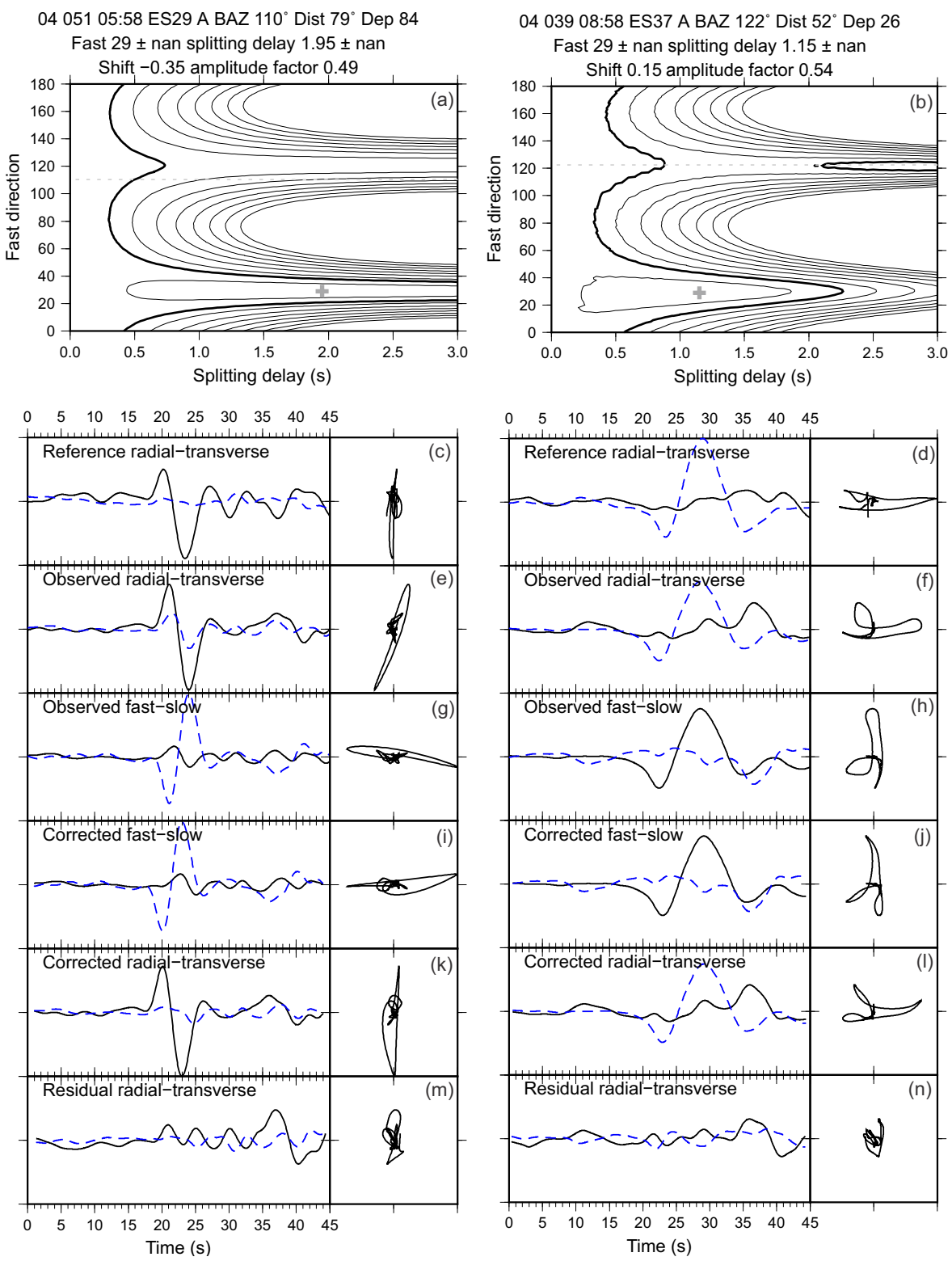

Figure 5. An example of null-anisotropy measurement based on the RST at stations ES29 and ES37. Panels on the left side represent the splitting measurement recorded at station pair ES27 (reference station)-ES29 (target station), and those on the right side represent the splitting measurement recorded at station pair ES05 (reference station)-ES37 (target station). The explanation for each panel is the same as in Fig. 3.

to complex anisotropy (e.g. Saltzer et al., 2000; Wüstefeld and Bokelmann, 2007); (iii) if the region itself is isotropic in nature. Following Eken and Tilmann (2014) and Singh et al. (2016), we use the $F$ test with the null-split rejection criteria to be able to avoid the contamination of the null measurement with the good splitting measurements. In this process, we calculate the theoretical residual energy under the assumption of null measurements and compare this with the observed residual energy at the minimum. Figure 5 shows two examples of null-splitting measurements at target stations ES29 and ES37, respectively. To ensure the stability of the results, we perform a stepwise quality assessment criterion before calculating the average splitting parameters at each station. To achieve this aim, we considered only those waveform pairs that have (i) a normalized residual energy $(\Delta E)$ smaller than 0.5 ; (ii) an amplitude correction factor parameter $(a)$ in between 0.4 and 0.6; and (iii) a $95 \%$ confidence level for nullsplitting rejection. We rejected the waveform pairs that have a $\phi$ error greater than $25^{\circ}$ and a delay time error greater than half of the delay time itself. After these quality assessments, we are left with only 3231 waveform pairs. At this stage of the processing, we perform another visual inspection to en- 
Table 1. List of the earthquakes used in this study.

\begin{tabular}{llrrrll}
\hline Event date & Event time & $\begin{array}{r}\text { Latitude } \\
\left({ }^{\circ}\right)\end{array}$ & $\begin{array}{r}\text { Longitude } \\
\left({ }^{\circ}\right)\end{array}$ & $\begin{array}{r}\text { Depth } \\
(\mathrm{km})\end{array}$ & Magnitude & Location site \\
\hline $2003 / 10 / 04$ & $14: 49: 02.7$ & -07.05 & +125.41 & 532.7 & 5.5 & Banda Sea \\
$2003 / 10 / 17$ & $17: 19: 53.6$ & -05.08 & +102.46 & 35.1 & 5.6 & Southern Sumatra, Indonesia \\
$2003 / 11 / 09$ & $19: 23: 28.6$ & +01.56 & +127.36 & 133.9 & 5.8 & Halmahera, Indonesia \\
$2004 / 02 / 08$ & $08: 58: 51.8$ & -03.66 & +135.34 & 25.7 & 5.7 & Irian Jaya Region, Indonesia \\
$2004 / 02 / 20$ & $05: 58: 45.2$ & -11.61 & +166.45 & 84.0 & 5.6 & Santa Cruz Islands \\
$2004 / 03 / 17$ & $05: 21: 00.8$ & +34.59 & +023.33 & 24.5 & 5.9 & Crete, Greece \\
$2004 / 03 / 26$ & $15: 20: 06.6$ & +41.86 & +144.21 & 22.4 & 5.7 & Hokkaidō, Japan region \\
$2004 / 04 / 09$ & $15: 23: 35.0$ & -13.17 & +167.20 & 228.4 & 5.8 & Vanuatu \\
$2004 / 05 / 28$ & $12: 38: 44.3$ & +36.25 & +051.62 & 17.0 & 6.2 & Northern and central Iran \\
$2004 / 06 / 22$ & $09: 04: 43.9$ & -10.90 & +166.26 & 152.8 & 5.8 & Santa Cruz Islands \\
$2004 / 06 / 30$ & $23: 37: 25.5$ & +00.80 & +124.73 & 90.8 & 6.0 & Minahassa Peninsula, Sulawesi \\
$2004 / 07 / 08$ & $10: 30: 49.2$ & +47.20 & +151.30 & 128.5 & 5.9 & Kuril Islands \\
$2004 / 07 / 25$ & $14: 35: 19.1$ & -02.43 & +103.98 & 582.1 & 6.8 & Southern Sumatra, Indonesia \\
$2003 / 07 / 27$ & $06: 25: 32.0$ & +47.15 & +139.25 & 470.3 & 6.3 & Primor'ye, Russia \\
$2004 / 08 / 02$ & $02: 36: 54.9$ & -05.47 & +102.62 & 40.5 & 5.5 & Southern Sumatra, Indonesia \\
$2004 / 08 / 07$ & $14: 18: 35.2$ & -06.24 & +095.67 & 20.7 & 5.8 & Southwest of Sumatra, Indonesia \\
$2004 / 08 / 28$ & $17: 00: 58.2$ & -08.69 & +157.25 & 10.0 & 5.5 & Solomon Islands \\
$2003 / 08 / 31$ & $23: 08: 00.3$ & +43.39 & +132.27 & 481.1 & 5.5 & Primor'ye, Russia \\
$2003 / 09 / 11$ & $21: 58: 25.5$ & -08.20 & +156.16 & 10.0 & 5.5 & Solomon Islands \\
$2004 / 09 / 15$ & $19: 10: 50.6$ & +14.22 & +120.41 & 115.4 & 6.0 & Luzon, Philippines \\
$2003 / 10 / 11$ & $00: 08: 49.1$ & +41.92 & +144.36 & 33.0 & 5.9 & Hokkaidō, Japan region \\
$2003 / 10 / 11$ & $01: 11: 31.2$ & +43.97 & +148.21 & 51.2 & 6.2 & East of Kuril Islands \\
$2003 / 10 / 17$ & $10: 19: 06.8$ & -05.47 & +154.15 & 133.0 & 6.2 & Solomon Islands \\
$2003 / 10 / 22$ & $11: 45: 30.8$ & -06.06 & +147.73 & 53.5 & 6.2 & Eastern New Guinea region \\
$2003 / 11 / 12$ & $08: 26: 43.7$ & +33.17 & +137.07 & 384.9 & 6.1 & Near S. coast of Honshū \\
\hline & & & & & &
\end{tabular}

hance the quality of our estimates, yielding only 501 very high-quality waveform pairs. These final waveforms show clear splitting and are free of any distortions due to signal processing. The remaining 501 waveform pairs are extracted from only 25 teleseismic events (Fig. 6) and are used to calculate the average splitting parameter at each station. The list of these 25 teleseismic events is provided in Table 1 . We apply the Von Mises approach (Cochran et al., 2003) to calculate the circular mean at each target stations for $\phi$ and an arithmetic mean is used for $\delta t$.

\subsection{Results}

We present here 501 splitting measurements observed for 42 seismic stations of the XE network between the years 2003 and 2004. The angular average of individual direct- $S$-derived splitting parameters $\left(\phi_{\mathrm{S}}\right.$ and $\left.\delta t_{\mathrm{S}}\right)$ at each station is given in Table 2. Station-averaged splitting parameters usually reflect significant anisotropy with large delay times $(>1 \mathrm{~s}$, Figs. 7 and 8) compared to those that could be considered negligible based on previously determined SKS-derived anisotropy parameters (Sol et al., 2007). For example, at station ES31 direct $S$ waves provide a relatively large time delay $(1.23 \mathrm{~s})$ although SKS splitting analysis performed by Sol et al. (2007) earlier resulted in a much smaller time delay time of about
$0.3 \mathrm{~s}$. Across the network, we observe considerable variation in direct $S$-wave-derived delay times ranging from 0.64 to $1.68 \mathrm{~s}$. In general, we observe the SW-NE to W-E trend in $\phi_{\mathrm{S}}$ before the edge margin of the southeastern Tibetan region. A consistent change in variation of $\phi_{\mathrm{S}}$ is observed further east where orientations take a sharp change from a SSW-ENE or W-E to a NW-SE direction (Fig. 7). We find significant splitting ( $\geq 0.64 \mathrm{~s})$ at seismic stations ES19, ES20, ES22, ES32, ES33, ES34, ES42, and ES45, where previously null or negligible splitting was observed in SKS waves (Sol et al., 2007). This could stem from multi-layered anisotropic orientations or insufficient amount of SKS-derived splitting measurements. This observation is inconsistent with an isotropic nature of the Indian lithosphere and indicates a complex 3D nature or more complex deformation pattern of the EHS. The scatter plot in Fig. 8 exhibits a comparison between estimated splitting parameters $\left(\phi_{\mathrm{S}}\right.$ and $\left.\delta t_{\mathrm{S}}\right)$ from the analysis of direct $S$ waves and previous SKS splitting measurements (Sol et al., 2007). The overall trend of the obtained splitting parameters $\left(\phi_{\mathrm{s}}\right)$ is consistent with the previous SKS measurement, whereas we observe larger time delays for the $S$ waves as compared to SKS phase.

We combine our splitting measurements with existing geodetic measurements (GPS velocity vectors and APM velocity vectors). We plot the GPS velocities by using pub- 
Table 2. Obtained average splitting parameters $\left(\phi_{\mathrm{S}}\right.$ and $\left.\delta t_{\mathrm{S}}\right)$ estimated from direct $S$ wave splitting measurement.

\begin{tabular}{|c|c|c|c|c|c|c|}
\hline Station & $\begin{array}{r}\text { Latitude } \\
\left(\left(^{\circ}\right)\right.\end{array}$ & $\begin{array}{r}\text { Longitude } \\
\left({ }^{\circ}\right)\end{array}$ & $\begin{array}{l}\phi_{\mathrm{S}} \\
\left(^{\circ}\right)\end{array}$ & $\begin{array}{l}\delta t_{\mathrm{s}} \\
(\mathrm{s})\end{array}$ & $\begin{array}{r}\text { Number of events } \\
\text { at a station }\end{array}$ & Contributing reference stations \\
\hline ES01 & 31.26 & 92.09 & 73.9 & 1.5 & 31 & $2,3,4,5,7,8,9,10,11,12,36,38,39,40,41$ \\
\hline ES02 & 31.00 & 92.54 & 75.7 & 1.5 & 26 & $1,3,4,5,7,8,9,10,11,12,13,38,40,41$ \\
\hline ES03 & 30.75 & 92.86 & 81.7 & 1.2 & 16 & $2,4,5,7,8,10,11,12,38,39,43$ \\
\hline ES04 & 30.65 & 93.25 & 91.5 & 1.2 & 11 & $1,3,5,7,8,10,11,12$ \\
\hline ES05 & 31.68 & 92.40 & 71.2 & 1.1 & 14 & $1,2,3,4,7,8,10,11,12,13$ \\
\hline ES07 & 31.48 & 93.70 & 93.8 & 1.0 & 15 & $1,2,3,4,5,8,9,10,11,12,14,38$ \\
\hline ES08 & 31.28 & 93.84 & 106.3 & 0.9 & 12 & $1,2,4,5,7,10,11,12,13$ \\
\hline ES09 & 31.91 & 93.06 & 81.5 & 1.1 & 15 & $1,3,5,8,10,11,12,13,14$ \\
\hline ES10 & 31.84 & 93.79 & 103.1 & 1.0 & 19 & $1,2,3,4,5,7,8,9,11,12,14,38$ \\
\hline ES11 & 31.91 & 94.14 & 96.2 & 1.2 & 25 & $1,2,3,4,5,7,8,9,10,12,14,36,38$ \\
\hline ES12 & 31.59 & 94.71 & 101.3 & 1.2 & 28 & $1,2,3,4,5,7,8,9,10,11,13,14,15,23,25,38$ \\
\hline ES13 & 31.54 & 95.28 & 88.5 & 1.4 & 15 & $2,4,9,11,12,13,14,15,26,30,36,38$ \\
\hline ES14 & 31.25 & 95.90 & 102.9 & 1.2 & 24 & $3,4,7,9,10,11,12,13,15,17,23,25,31$ \\
\hline ES15 & 31.19 & 96.50 & 104.2 & 1.0 & 09 & $11,12,14,16,25,36,38$ \\
\hline ES16 & 31.18 & 97.02 & 117.0 & 1.4 & 01 & 13 \\
\hline ES17 & 31.27 & 97.55 & 135.4 & 1.0 & 11 & $18,23,25,31$ \\
\hline ES18 & 31.30 & 97.96 & 122.0 & 0.8 & 02 & 17 \\
\hline ES19 & 30.81 & 95.71 & 106.6 & 1.5 & 09 & $3,4,7,8,11,12,38$ \\
\hline ES20 & 30.73 & 96.10 & 108.0 & 0.9 & 01 & 11 \\
\hline $\mathrm{ES} 22$ & 30.81 & 96.70 & 110.0 & 0.9 & 01 & 14 \\
\hline ES23 & 30.69 & 97.26 & 96.2 & 1.0 & 16 & $12,15,25,31$ \\
\hline $\mathrm{ES} 24$ & 30.50 & 97.14 & 106.0 & 1.1 & 03 & 13,15 \\
\hline ES25 & 30.12 & 97.30 & 121.1 & 0.9 & 10 & $18,23,31$ \\
\hline ES26 & 29.96 & 97.51 & 142.2 & 1.0 & 03 & $14,30,31$ \\
\hline $\mathrm{ES} 27$ & 29.64 & 97.90 & 130.0 & 1.1 & 01 & 26 \\
\hline ES29 & 30.01 & 96.69 & 84.0 & 1.1 & 16 & $14,15,23,25,31$ \\
\hline ES30 & 29.32 & 97.19 & 110.8 & 1.1 & 07 & $25,26,27,31$ \\
\hline ES31 & 29.51 & 96.76 & 82.4 & 1.2 & 16 & $14,17,25,26,30,31$ \\
\hline ES32 & 29.76 & 96.10 & 103.0 & 1.4 & 02 & 13,30 \\
\hline ES33 & 29.77 & 95.70 & 67.1 & 0.6 & 10 & $3,7,11,12,14,15,30,38$ \\
\hline ES34 & 29.91 & 95.47 & 84.8 & 1.2 & 20 & $3,4,7,8,10,11,12,14,15,16,36,38$ \\
\hline ES35 & 29.96 & 94.78 & 111.9 & 1.1 & 09 & $1,4,10,14,15,16,31,36,38$ \\
\hline ES36 & 29.81 & 93.91 & 86.2 & 1.1 & 13 & $1,4,5,7,8,11,13,14,15,38,40,41$ \\
\hline ES37 & 29.90 & 93.51 & 80.5 & 1.4 & 07 & $1,10,13,36,39,40,41$ \\
\hline ES38 & 30.02 & 92.97 & 72.5 & 1.2 & 18 & $3,4,5,7,8,10,11,12,36,39,40,41$ \\
\hline ES39 & 29.87 & 92.62 & 75.8 & 1.6 & 17 & $1,2,3,4,8,9,10,11,36,38,40,41$ \\
\hline ES40 & 29.71 & 92.15 & 78.0 & 1.4 & 14 & $1,2,4,5,7,8,10,36,38,39,41,43$ \\
\hline ES41 & 29.19 & 91.76 & 70.4 & 1.7 & 14 & $2,3,4,5,36,38,40$ \\
\hline $\mathrm{ES} 42$ & 28.90 & 91.94 & 108.6 & 1.6 & 06 & $1,37,39$ \\
\hline ES43 & 29.04 & 92.23 & 75.4 & 1.2 & 05 & $8,36,38,39$ \\
\hline ES45 & 29.12 & 93.78 & 65.8 & 1.3 & 05 & $7,8,38$ \\
\hline ES46 & 29.25 & 94.26 & 89.2 & 1.1 & 04 & 10,36 \\
\hline
\end{tabular}

lished data of Chen et al. (2000), Zhang et al. (2004), Shen et al. (2005), and Sol et al. (2007). The APM velocities are calculated via a web-based plate motion calculator (https://www.unavco.org/software/geodetic-utilities/ plate-motion-calculator/plate-motion-calculator.html) that is based on an integrated global plate motion model (GSRMv1.2) originally developed by Kreemer et al. (2003). Figure 9 shows the correlative analysis of splitting parameters by using direct $S$ phases, APM directions, and GPS mea- surements in our target region. It suggests that the observed anisotropy is not only due to lithospheric deformation or due to asthenospheric dynamics at the base of the lithosphere but that it is a combined effect of both. 


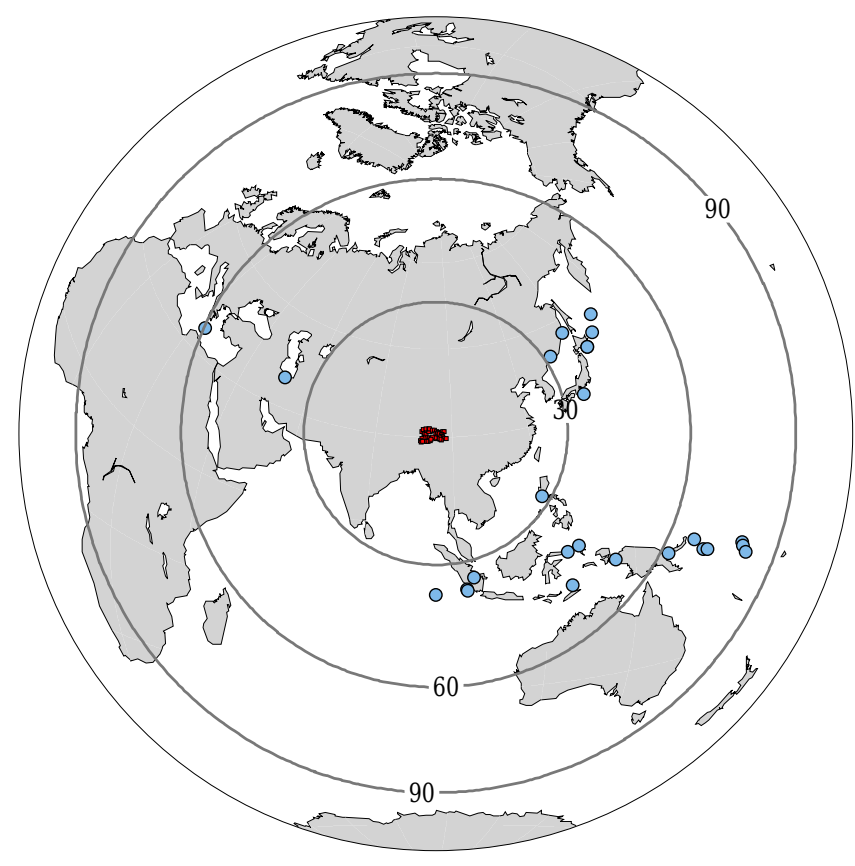

Figure 6. Epicentral distribution of teleseismic earthquakes used in the study $\left(30-90^{\circ}\right)$. Rectangles indicate seismic stations in this study.

\subsection{Discussion}

\subsection{Origin of anisotropy in the southeastern Tibetan region}

Our resultant splitting measurements vary over a range of $\delta t_{\mathrm{S}}$ suggesting the presence of a significant deformation in the region. The fast polarization directions are rather consistent and match well with the surface geology, similar to those observed from the SKS phases in Sol et al. (2007). The fast directions closely follow the strike of the major sutures like BNSZ and ITSZ and surface strain fields as observed through GPS and are under the influence of bending at the EHS (Fig. 7). FPDs that are parallel to the surface geologic features such as faults (e.g. Savage, 1999; Flesch et al., 2005) are indicative of vertically coherent deformation of the crust and upper mantle. This has previously been invoked to explain the anisotropic character in eastern and northeastern Tibet (Holt et al., 2000; León Soto et al., 2012; Eken et al., 2013; Eken and Tilmann, 2014). In the absence of any compelling evidence for crust-mantle coupling, we argue in favour of a large-scale deformation of the crust and upper mantle under similar boundary conditions as a plausible option to explain the observed anisotropy (Flesch et al., 2005; Sol et al., 2007; Holt et al., 2000).

The observed large time delays ( $>1 \mathrm{~s}$ ), in this study, reflect a highly anisotropic region with similar deformation patterns at depths. The presence of a more complex anisotropic structure (e.g. double layer) with different orientations in the fast axis at various depths may result in smaller delay times (Saltzer et al., 2000). In the western Himalayan region, Vinnik et al. (2007) observed different fast-velocity directions for seismic azimuthal anisotropy that vary from $\mathrm{N} 60^{\circ} \mathrm{E}$ at depths between 80 and $160 \mathrm{~km}$ to $\mathrm{N} 150^{\circ} \mathrm{E}$ at depths between 160 and $220 \mathrm{~km}$ depth by using the joint inversion of SKS particle motions and $P$ receiver functions. This provides an argument to explain the null or negligible anisotropy as reported from the same region using SKS phases (Sandvol et al., 1994). Smaller time delays in the Nepal Himalayas and the Sikkim Himalayas are attributed to the combined effect of shear at the base of the lithosphere due to APM-related strain of the Indian Plate and ductile flow along the collision front due to compression, with possibly completely different orientations (Singh et al., 2007). Sol et al. (2007) reported null measurements at a few stations, possibly due to the lack of clear splitting measurements of SKS phases. The transition between deformation types at the boundaries of the Indian and Eurasian lithospheric plates was considered to be the main reason for observed null or negligible anisotropy further west beneath the southern Tibetan Plateau (Chen et al., 2010; Chen and Ozalaybey, 1998; Barruol and Hoffmann, 1999; Zhao et al., 2014). The lack of anisotropy beneath southern Tibet was mainly explained by an isotropic nature of the Indian tectonic plate or a lack in the ability of SKS phases to sample the anisotropy due to a sub-vertical mantle shear strain field created by downwelling Indian lithosphere (Singh et al., 2007; Sandvol et al., 1997). However, the hypothesis of an isotropic nature of the Indian lithosphere was contradicted in various studies (Singh et al., 2006, 2007; Kumar and Singh, 2008), and significant anisotropy is reported beneath Tibet in the region of null measurement (Gao and Liu, 2009; Singh et al., 2016).

Sub-vertical shear strain or complex flow arises due to the subducting Indian slab and may result in null or negligible anisotropy (Sandvol et al., 1997; Fu et al., 2008). Recent tomographic studies (Griot et al., 1998; Huang et al., 2003; Zhou and Murphy, 2005; Yao et al., 2008; Priestley et al., 2006; Singh et al., 2014; Pandey et al., 2014) suggest that in the western Tibetan side, where the N-S extension is less, the Indian lithosphere is supposed to extend as far as the Jinsa River suture zone (JRSZ; Zhao et al., 2010), while in the eastern Tibet side, the Indian lithosphere extends up to the ITSZ (Li et al., 2008; Zhao et al., 2010). A combined study using seismic anisotropy and Bouguer gravity anomalies place the Indian mantle front up at $33^{\circ} \mathrm{N}$ in central Tibet (Chen et al., 2010). In this segment of the Himalaya-Tibet collision zone, the northern limit of the Indian lithospheric mantle does not seem to extend beyond the ITSZ (Li et al., 2008). The lack of anisotropy reported using SKS/SKKS phases (Sol et al., 2007) at a few seismic stations might be due to insufficient measurements rather than the effects of the downwelling Indian lithosphere as suggested in southern Tibet (Sandvol et al., 1997). By adding a considerably large amount of measurements from direct $S$ waves, we ob- 

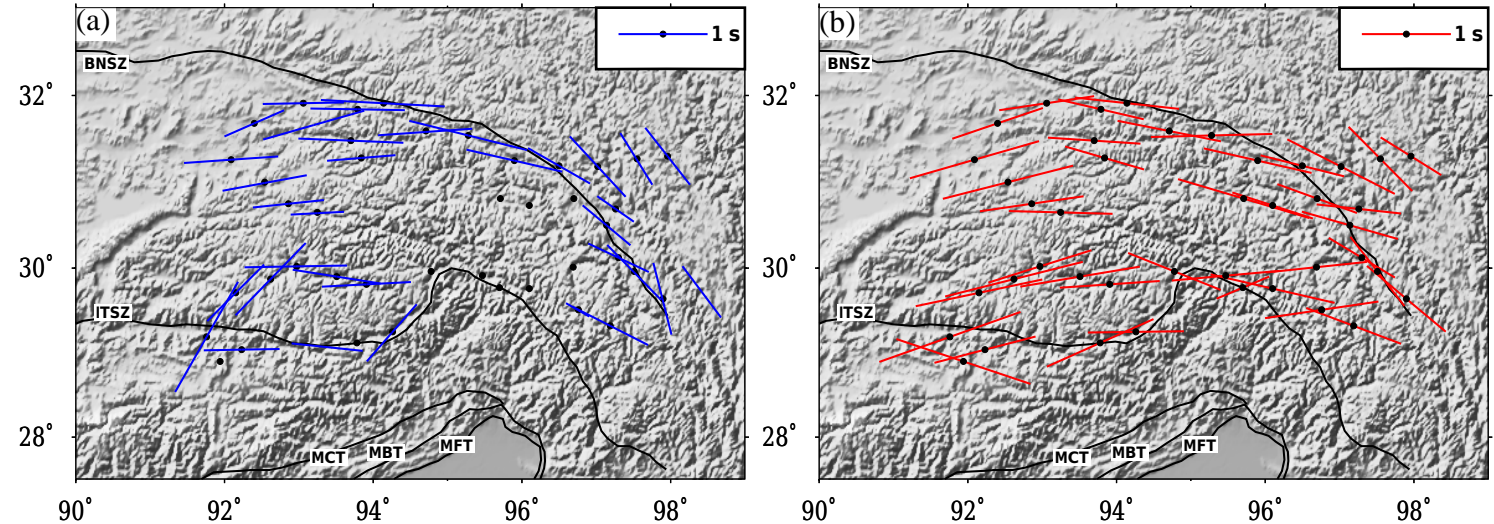

Figure 7. The tectonic and topographic map of the southeastern Tibetan region, which represents the station average splitting parameters: (a) the previous SKS-derived splitting measurements (solid blue bar) performed by Sol et al. (2007) and (b) the direct $S$-wave-derived splitting measurements (solid red bar, this study). The length of the solid bars in each panel indicates the strength of anisotropy and is scaled by station-averaged splitting time delays. Azimuth of the solid bars indicates the fast polarization direction (FPD). Black circles show location of the seismic stations used in this study. (MFT: Main Frontal Thrust; MBT: Main Boundary Thrust; MCT: Main Central Thrust; ITSZ: Indus-Tsangpo suture zone; BNSZ: Bangong-Nujiang suture zone).
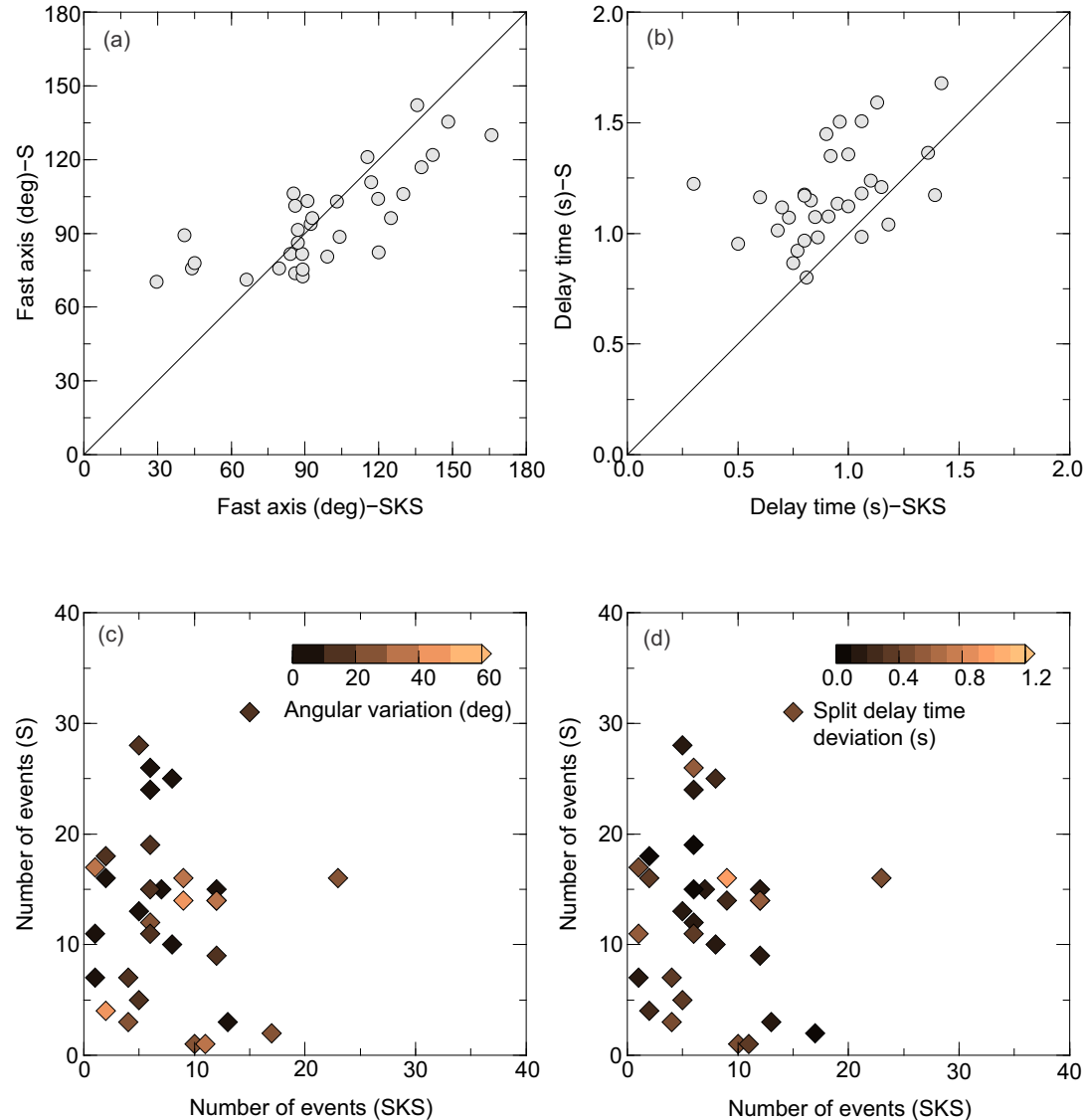

Figure 8. Comparison of SKS and $S$-wave-derived station-averaged splitting parameters in the study region. Panels (a) and (b): scatter plots that compare SKS- and $S$-derived FPDs and split time delays (TDs), respectively. (c) Scatter plot of the number of individual SKS splitting measurement and the number of events used in direct $S$ splitting measurement (this study). Note that each station here is colour-coded by its absolute deviation value that is obtained by subtracting $S$ - and SKS-derived FPDs. (d) The same plot for the misfit between SKS- and $S$-derived station-averaged split TDs. Average SKS splitting parameters used in this figure are taken from Sol et al. (2007). 

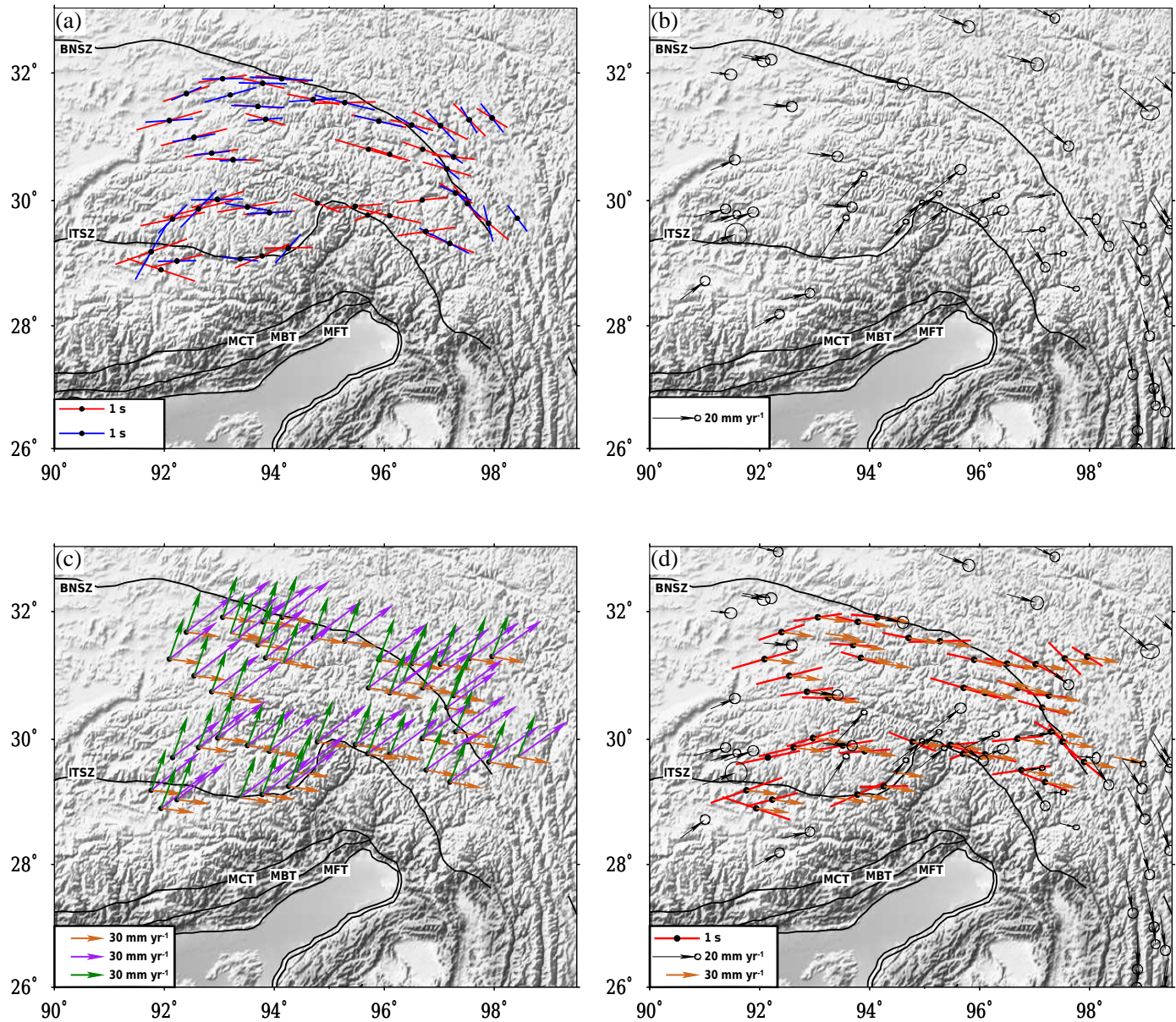

Figure 9. Lateral variations of anisotropic, geodetic, and absolute plate motion data shown over topographic and tectonic features of the study area. (a) Map view comparison between the splitting measurement inferred from direct $S$ waves (this study shown by red bars) and SKS splitting measurements (Sol et al., 2007, in blue bars). (b) The Global Positioning System (GPS) velocity (mm yr ${ }^{-1}$ ) vectors (black arrows) around SE Tibetan region calculated with respect to the South China reference frame and stable Eurasia. GPS data is compiled from several studies including Chen et al. (2000), Zhang et al. (2004), Shen et al. (2005), and Sol et al. (2007). (c) Absolute plate motion (APM) velocities calculated through https://www.unavco.org/software/geodetic-utilities/plate-motion-calculator/platemotion-calculator.html by using the GSRM v1.2 (2004) model of Kreemer et al. (2003). Note that arrows in brown, green, and purple represent the APM velocities of the Eurasian Plate in no net rotation frame, of the Indian Plate with respect to the Eurasian Plate, and the motion of the Indian Plate in no net rotation frame, respectively. (d) Map view comparisons of the station (black circle) average direct $S$-wave-derived splitting parameters with GPS velocity (black arrow) and APM (brown arrow) vectors. Abbreviations on the maps: MFT: Main Frontal Thrust; MBT: Main Boundary Thrust; MCT: Main Central Thrust; ITSZ: Indus-Tsangpo suture zone; BNSZ: Bangong-Nujiang suture zone; JRSZ: Jinsa River suture zone.

serve significant anisotropy for the same stations and fast axis deformation, which can be explained by eastward flow in a lithospheric crush zone formed due to the collision of the Indian and Asian tectonic plates as suggested for southern Tibet (Zhao et al., 2014).

The crust beneath Tibet is thick ( $\sim 80 \mathrm{~km}$; e.g. Singh et al., 2015) and crustal anisotropic effects should be accounted for in the splitting measurements obtained using direct $S$ and SKS/SKKS phases. In the Himalayan region, highly anisotropic crust $(\sim 20 \%)$ has been reported using an inversion of receiver functions (Schulte-Pelkum et al., 2005; Singh et al., 2010), while a similar approach at a few seismic stations covering Tibet suggests approximately 4-14\% seismic anisotropy within the Tibetan crust (Sherrington et al., 2004; Ozacar and Zandt, 2004). Ozacar and Zandt (2004) have accounted for splitting of $<0.5 \mathrm{~s}$ over SKS split times due to the observed anisotropy of $>10 \%$ in the crust. Splitting times of $0.2-0.3 \mathrm{~s}$ are observed within the eastern Tibet crust using splitting of the Moho-converted Ps phases (receiver functions, Chen et al., 2013). Tomographic (Huang et al., 2002, 2009; Hung et al., 2010; Yao et al., 2008, 2010; Li et al., 2009), magnetotelluric (Bai et al., 2010), and gravity (Jordan and Watts, 2005) studies of the SE Tibetan region suggest ductile flow in the deeper region of the crust. Rel- 
atively low seismic velocities are resolved for shear waves in tomographic studies at these crustal depths, indicating localized flow of the crustal material along a network of strikeslip faults in the region (Yao et al., 2010). These types of flow may produce splitting orientations similar to lower lithospheric scales with coherent deformation. A coupled crust and mantle increases the SKS delay times by $0.2-0.5 \mathrm{~s}$ due to the effects of crust. The anisotropic orientations observed beneath most parts of Tibet (Sherrington et al., 2004; Ozacar and Zandt, 2004; Chen et al., 2013) within the crust are completely different from the SKS or direct $S$ waves, implying that the types of deformation in the crust and upper mantle could be different; this does not indicate a coherent deformation pattern, at least in some parts of Tibet. A possible explanation for such decoupling could be that the crustal anisotropic parameters are influenced by either current deformation or fossilized fabric with different boundary conditions at mid-crustal and lower crustal levels.

\subsection{Comparison between direct $S$ - and SKS-derived splitting parameters}

The scatter plot in Fig. 8a, b provides a comparison between estimated splitting parameters $\left(\phi_{\mathrm{s}}\right.$ and $\left.\delta t_{\mathrm{s}}\right)$ from the analysis of direct $S$ waves and previous SKS splitting measurements (Sol et al., 2007). The obtained splitting parameters $\left(\phi_{\mathrm{S}}\right)$ from the direct $S$ wave measurements show that they are consistent with previous SKS-based measurements. Overall, the consistency between splitting parameters inferred from SKS and direct $S$ waves is most likely because both are derived from the same type of large-scale anisotropic structures. Large differences between SKS- and $S$-derived $\delta t_{\mathrm{s}}$ that appear as a move-out in the scatter plot occur for three reasons: (i) longer $S$ wave ray paths as compared to SKS ray paths sampling the same type of large-scale anisotropy, (ii) an increase in the number of the events (Fig. 8c, d) sampling different azimuths that contribute to the direct $S$ wave measurements as compared to the SKS, and (iii) the $S$-derived type of anisotropy might show strong variation in splitting with incident angle, i.e. an event coming from different azimuths. The precision of our results is evident from small deviations in Fig. 8c, $\mathrm{d}$, and this is most likely due to the involvement of a relatively increased number of observations from both $S$ and SKS phases in splitting measurements. Figure $8 \mathrm{c}$ shows that the absolute deviation for $\phi_{\mathrm{S}}$ is no larger than $25^{\circ}$ except at 7 out of 42 stations (namely ES23, ES27, ES31, ES39, ES40, ES41, and ES46), where we observe large deviations of up to $48^{\circ}$. An extreme example of maximum deviation for $\delta t_{\mathrm{S}}$ is at station ES31. The deviation for $\phi_{\mathrm{s}}$ is also relatively large $\left(>30^{\circ}\right)$. Because station ES31 does not suffer from a lack of data, (8 observations for SKS and 14 for $S$ ), we infer that the mismatch may be a result of the use of an incorrect reference anisotropy when correcting for receiverside anisotropy. Overall, deviations for $\delta t_{\mathrm{s}}$ are smaller than $0.56 \mathrm{~s}$. In general, we observe relatively more events for the direct $S$ waves compared to individual SKS phases except at stations ES16, ES18, ES23, ES26, and ES27. For these five stations, we detect deviations for $\phi_{\mathrm{S}}$ and $\delta t_{\mathrm{S}}$ of up to $36^{\circ}$ and $0.5 \mathrm{~s}$, respectively. In summary, our comparative analysis of splitting parameters shows a good accordance between SKS- and direct- $S$-derived splitting parameters as previously observed in the Himalaya-Tibet collision zone (e.g. McNamara et al., 1994; Singh et al., 2016; Huang et al., 2011; Eken et al., 2013) and in the Indian shield (Saikia et al., 2010).

\subsection{Deformation pattern revealed from the comparison of the GPS, APM, and splitting measurements}

Previous studies on seismic anisotropy (McNamara et al., 1994; Sol et al., 2007; Huang et al., 2000, 2007; Wang et al., 2007, 2008; Chen et al., 2013; Zhao et al., 2014; Guilbert et al., 1996; Bai et al., 2009) that compared splitting parameters with APM, GPS, and structural and topographical features provide crucial information concerning the dynamic deformation pattern and possible linkage of the strength of coupling between the crust and lithospheric mantle of the southeastern or eastern Tibetan region. We observe a sharp transition in the spatial distribution of $\phi_{\mathrm{s}}$ from nearly W$\mathrm{E}$ in the western part of the study region to nearly NW-SE or NNW-SSE near the southeastern Tibetan margin (Fig. 9). The structural and topographical features, such as major suture zones and mountain belts, tend to rotate around the EHS from nearly E-W or ENE-WSW to N-S or NE-SW (Hallet and Molnar, 2001; Booth et al., 2004). The observed $\phi_{\mathrm{s}}$ and GPS velocity vectors follow a similar trend (Fig. 9a, b). The APM directions are consistent with the present ongoing asthenospheric flow (Vinnik et al., 1992, 1995; Vinnik and Montagner, 1996). By using different plots of the plate motion (APM of Eurasian and Indian plates referenced to the no-net-rotation (NNR) frame or the relative plate motion of the Indian Plate referenced to the Eurasian Plate), we want to examine the contribution of APM to explaining the observed anisotropic variation and to check which plate motion best explains the observed $\phi_{\mathrm{s}}$ of the splitting measurements. But the observed $\phi_{\mathrm{s}}$ are not consistent with plate motion. The discrepancy between the $\phi_{\mathrm{S}}$ and APM may indicate that the obtained splitting, and hence the anisotropic behaviour of the study area, is not only due to asthenospheric dynamics but is a combined effect of the lithospheric deformation and asthenospheric dynamics. The lateral variation of obtained splitting measurements, when taken together with GPS velocity vectors, geological features, and the APM directions, depicts the movement of lithospheric or crustal material of the western and central plateau relative to the Eurasian Plate towards the eastern Tibetan side and clockwise rotation around the EHS. This supports the presence of a deep crustal flow and movement of material from the central and western portion towards the eastern Tibetan side as has been suggested previously by Royden et al. $(1997,2008)$. 
The present-day GPS measurements do not necessarily reveal the deformation of the whole crust but could be associated with deformation of the shallow crust (Chen et al., 2013). Seismic imaging of crustal anisotropy based on receiver function studies (e.g. Sherrington et al., 2004; Chen et al., 2013) supports this argument. The orientation of the GPS velocity vectors and the $\phi_{\mathrm{s}}$ of the direct $S$ waves only match when the orientation of the different layers of anisotropy within the crust and mantle tend to be similar. Griot et al. (1998), Holt et al. (2000), Fouch et al. (2000), and Sol et al. (2007) discuss the coupling and decoupling of the crust and mantle by making comparisons among $\phi_{\mathrm{s}}$, GPS, APM, and surficial features. Sol et al. (2007) report a good coherency between anisotropic and geodetic measurements for the entire southeastern Tibetan region, and on that basis, they discuss the coupling of the crustal and mantle material as similarly observed in the northeast Tibetan Plateau (e.g. Eken et al., 2013; Eken and Tilmann, 2014). The seismic anisotropy directions that were previously obtained from the inversion of receiver functions, however, do not suggest vertically coherent deformation of the crust (e.g. Ozacar and Zandt, 2004; Sherrington et al., 2004). Sherrington et al. (2004) report 4-14\% seismic anisotropy with variable orientations at different depths. They attribute varying patterns of anisotropic directions to both fossilized fabric and more recent deformation. The different orientations at mid and lower crustal levels do not necessarily support a coherent deformation of the crust and upper mantle.

On the basis of driving forces, two kinematic models have been proposed to explain the coupling-decoupling of the crust and lithospheric mantle. The first one is a simple asthenospheric model (Richardson, 1992), proposed to explain the decoupling of the crust and mantle by the intrusion of a mechanically weak layer, such as the asthenosphere, into the crust. Whenever a mechanically weak layer is present in between the crust and mantle, the force acting on the crustal region cannot be transmitted into the mantle. As a result, the crust is decoupled from the mantle due to different driving forces on them. In such models, the velocity difference between the top and bottom of the mechanically weak layer gives rise to mantle deformation, and that difference is parallel to the fast polarization direction. The second model, proposed by Lithgow-Bertelloni and Richards (1998), is the vertically coherent model, and it explains the coupling of the materials within the crust and lithospheric mantle on the basis of the transmission of the buoyancy forces from the crust to the mantle. This model requires a rigid lower part of the crust. In contrast, low shear wave velocity anomalies resolved in various tomographic studies recently (Huang et al., 2002, 2009; Hung et al., 2010; Yao et al., 2008; Li et al., 2009) have indicated a weak layer in the deeper region of the crust beneath the SE Tibetan region. It is noteworthy to mention that we avoid making any comment on the possible linkage between the deformation and coupling of the crust and underlying lithospheric mantle by only using splitting parameters inferred from direct $S$ waves and geodetic measurements, and further study is required.

\section{Conclusions}

Our splitting observations using direct $S$ waves add new constraints in understanding the deformation pattern and its causes in the southeastern Tibetan region near Namcha Barwa. We list the main concluding remarks from the present study as follows:

1. The observed splitting analysis suggests a highly deformed crust and lithospheric mantle.

2. Significant anisotropy at stations where null or negligible anisotropy is reported based on previous SKS splitting measurements is inconsistent with the hypothesis of an isotropic lithospheric mantle.

3. Our study also provides clear evidence for the development of anisotropy in this region with active geodynamic implications for several tectonic events, i.e. the multistage subduction of the Indian Plate below the Eurasian Plate and the movement of the western central Tibetan lithospheric material towards the southeastern and eastern Tibetan side.

4. The observed splitting delays (0.67-1.68 s) suggest the possible existence of a multi-layered anisotropy structure in the crust and upper mantle. Further understanding of this requires 3-D geodynamic modelling and inversion of multi-frequency datasets to resolve more complex depth-dependent anisotropic structures (e.g. multi-layer anisotropy and dipping axis of symmetry).

Code and data availability. The multisplit $\mathrm{C}++$ code used for carrying out splitting measurements of the direct $S$ waveforms is available with a General Public License (GPL) at http://github.com/ ftilmann/multisplit. The waveform data used in this study are downloaded from the Incorporated Research Institutions for Seismology Data Management Center (IRIS-DMC) data archive system, Namcha Barwa Tibet network code XE (2003-2004).

Competing interests. The authors declare that they have no conflict of interest.

Acknowledgements. The IRIS data management centre and Project team of Namcha Barwa Seismic Network (PASSCAL) are gratefully acknowledged for making the seismic data available. This work has been performed under the ISIRD project (ASI) of IIT Kharagpur. Tuna Eken thanks the Alexander von Humboldt $(\mathrm{AvH})$ Foundation for the equipment subsidy. We benefited from valuable comments by Frederik Tilmann during the preparation 
of the revised version of the paper. We thank topical editor Charlotte Krawczyk, reviewer Rob Porritt, and one anonymous reviewer for their valuable comments and suggestions, which helped us to improve the paper substantially.

Edited by: C. Krawczyk

Reviewed by: R. Porritt and one anonymous referee

\section{References}

Argand, E.: La tectonique de l'Asie, Int. geol, Congr. Rep, 171-322, 1924.

Bai, D., Unsworth, M. J., Meju, M. A., Ma, X., Teng, J., Kong, X., Sun, Y., Sun, J., Wang, L., Jiang, C., Zhao, C., Pengfei, X., and Liu, M.: Crustal deformation of the eastern Tibetan plateau revealed by magnetotelluric imaging, Nat. Geosci., 3, 358-362, doi:10.1038/ngeo830, 2010.

Bai, L., Iidaka, T., Kawakatsu, H., Morita, Y., and Dzung, N.: Seismic anisotropy and shear-wave splitting in lower-crustal and upper-mantle rocks from the Ivrea Zone - experimental and calculated data, Phys. Earth Planet. In., 176, 33-43, doi:10.1016/j.pepi.2009.03.008, 2009.

Barruol, G. and Hoffmann, R.: Upper mantle anisotropy beneath the Geoscope stations, J. Geophys. Res., 104, 10757-10773, doi:10.1029/1999JB900033, 1999.

Becker, T. W. and Faccenna, C.: Mantle conveyor beneath the Tethyan collisional belt, Earth Planet. Sc. Lett., 310, 453-461, doi:10.1016/j.eps1.2011.08.021, 2011.

Booth, A. L., Zeitler, P. K., Kidd, W. S., Wooden, J., Liu, Y., Idleman, B., Hren, M., and Chamberlain, C. P.: U-Pb zircon constraints on the tectonic evolution of southeastern Tibet, Namche Barwa Area, Am. J. Sci., 304, 889-929, doi:10.2475/ajs.304.10.889, 2004.

Chen, W.-P. and Ozalaybey, S.: Correlation between seismic anisotropy and Bouguer gravity anomalies in Tibet and its implications for lithospheric structures, Geophys. J. Int., 135, 93-101, doi:10.1046/j.1365-246X.1998.00611.x, 1998.

Chen, W.-P., Martin, M., Tseng, T.-L., Nowack, R. L., Hung, S.-H., and Huang, B.-S.: Shear-wave birefringence and current configuration of converging lithosphere under Tibet, Earth Planet. Sc. Lett., 295, 297-304, doi:10.1016/j.epsl.2010.04.017, 2010.

Chen, Y., Zhang, Z., Sun, C., and Badal, J.: Crustal anisotropy from Moho converted Ps wave splitting analysis and geodynamic implications beneath the eastern margin of Tibet and surrounding regions, Geophys. Res. Lett., 24, 946-957, doi:10.1016/j.gr.2012.04.003, 2013.

Chen, Z., Burchfiel, B., Liu, Y., King, R., Royden, L., Tang, W., Wang, E., Zhao, J., and Zhang, X.: Global Positioning System measurements from eastern Tibet and their implications for India/Eurasia intercontinental deformation, J. Geophys. Res., 105, 16215-16227, doi:10.1029/2000JB900092, 2000.

Cochran, E. S., Vidale, J. E., and Li, Y.-G.: Near-fault anisotropy following the Hector Mine earthquake, J. Geophys. Res., 108, 2436, doi:10.1029/2002JB002352, 2003.

Confal, J. M., Eken, T., Tilmann, F., Yolsal-Çevikbilen, S., ÇubukSabuncu, Y., Saygin, E., and Taymaz, T.: Investigation of mantle kinematics beneath the Hellenic-subduction zone with teleseis- mic direct shear waves, Phys. Earth Planet. In., 261, 141-151, doi:10.1016/j.pepi.2016.10.012, 2016.

Eken, T. and Tilmann, F.: The Use of Direct Shear Waves in Quantifying Seismic Anisotropy: Exploiting Regional Arrays, B. Seismol. Soc. Am., 104, 2644-2661, doi:10.1785/0120140020, 2014.

Eken, T., Tilmann, F., Mechie, J., Zhao, W., Kind, R., Su, H., Xue, G., and Karplus, M.: Seismic Anisotropy from SKS Splitting beneath Northeastern Tibet, B. Seismol. Soc. Am., 103, 3362 3371, doi:10.1785/0120130054, 2013.

Flesch, L. M., Haines, A. J., and Holt, W. E.: Dynamics of the IndiaEurasia collision zone, J. Geophys. Res., 106, 16435-16460, doi:10.1029/2001JB000208, 2001.

Flesch, L. M., Holt, W. E., Silver, P. G., Stephenson, M., Wang, C.-Y., and Chan, W. W.: Constraining the extent of crust - mantle coupling in central Asia using GPS, geologic, and shear wave splitting data, Earth Planet. Sc. Lett., 238, 248-268, doi:10.1016/j.epsl.2005.06.023, 2005.

Fouch, M. J., Fischer, K. M., Parmentier, E. M., Wysession, M. E., and Clarke, T. J.: Shear wave splitting, continental keels, and patterns of mantle flow, J. Geophys. Res., 105, 6255-6275, doi:10.1029/1999JB900372, 2000.

Fu, Y. V., Chen, Y. J., Li, A., Zhou, S., Liang, X., Ye, G., Jin, G., Jiang, M., and Ning, J.: Indian mantle corner flow at southern Tibet revealed by shear wave splitting measurements, Geophys Res. Lett., 35, L02308, doi:10.1029/2007GL031753, 2008.

Gao, S. S. and Liu, K. H.: Significant seismic anisotropy beneath the southern Lhasa Terrane, Tibetan Plateau, Geochem. Geophy. Geosy., 10, Q02008, doi:10.1029/2008GC002227, 2009.

Garzanti, E. and Van Haver, T.: The Indus clastics: forearc basin sedimentation in the Ladakh Himalaya (India), Sediment. Geol., 59, 237-249, doi:10.1016/0037-0738(88)90078-4, 1988.

Griot, D.-A., Montagner, J.-P., and Tapponnier, P.: Phase velocity structure from Rayleigh and Love waves in Tibet and its neighboring regions, J. Geophys. Res., 103, 21215-21232, doi:10.1029/98JB00953, 1998.

Guilbert, J., Poupinet, G., and Mei, J.: A study of azimuthal $P$ residuals and shear-wave splitting across the Kunlun range (Northern Tibetan plateau), Phys. Earth Planet. In., 95, 167-174, doi:10.1016/0031-9201(95)03120-0, 1996.

Hallet, B. and Molnar, P.: Distorted drainage basins as markers of crustal strain east of the Himalaya, J. Geophys. Res., 106, 1369713709, doi:10.1029/2000JB900335, 2001.

Henderson, A. L., Najman, Y., Parrish, R., Mark, D. F., and Foster, G. L.: Constraints to the timing of India-Eurasia collision, a reevaluation of evidence from the Indus Basin sedimentary rocks of the Indus-Tsangpo Suture Zone, Ladakh, India, Earth-Sci. Rev., 106, 265-292, doi:10.1016/j.earscirev.2011.02.006, 2011.

Herquel, G., Wittlinger, G., and Guilbert, J.: Anisotropy and crustal thickness of northern-Tibet. New constraints for tectonic modelling, Geophys. Res. Lett., 22, 1925-1928, doi:10.1029/95GL01789, 1995.

Hirn, A., Jiang, M., Sapin, M., Diaz, J., Nercessian, A., and $\mathrm{Lu}$, Q.: Seismic anisotropy as an indicator of mantle flow beneath the Himalayas and Tibet, Nature, 375, 571-574, doi:10.1038/375571a0, 1995.

Holt, W., Chamot-Rooke, N., Le Pichon, X., Haines, A., Shen-Tu, B., and Ren, J.: Velocity field in Asia inferred from Quaternary fault slip rates and Global Positioning System observations, J. 
Geophys. Res., 105, 19185-19209, doi:10.1029/2000JB900045, 2000.

Holt, W. E., Li, M., and Haines, A.: Earthquake strain rates and instantaneous relative motions within central and eastern Asia, Geophys. J. Int., 122, 569-593, doi:10.1111/j.1365246X.1995.tb07014.x, 1995.

Houseman, G. and England, P.: Finite strain calculations of continental deformation: 1. Method and general results for convergent zones, J. Geophys. Res., 91, 3651-3663, doi:10.1029/JB091iB03p03651, 1986.

Houseman, G. and England, P.: Crustal thickening versus lateral expulsion in the Indian-Asian continental collision, J. Geophys. Res., 98, 12233-12249, doi:10.1029/93JB00443, 1993.

Houseman, G. and England, P.: A lithospheric-thickening model for the Indo-Asian collision, World and Regional Geology, 1, 1-17, 1996.

Huang, J., Zhao, D., and Zheng, S.: Lithospheric structure and its relationship to seismic and volcanic activity in southwest China, J. Geophys. Res., 107, ESE 13-1-ESE 13-14, doi:10.1029/2000JB000137, 2002.

Huang, W.-C., Ni, J. F., Tilmann, F., Nelson, D., Guo, J., Zhao, W., Mechie, J., Kind, R., Saul, J., Rapine, R., and Hearn, T. M.: Seismic polarization anisotropy beneath the central Tibetan Plateau, J. Geophys. Res., 105, 27979-27989, doi:10.1029/2000JB900339, 2000.

Huang, Z., Wang, L., Xu, M., Liu, J., Mi, N., and Liu, S.: Shear wave splitting across the Ailao Shan-Red River fault zone, SW China, Geophys. Res. Lett., 34, L20301, doi:10.1029/2007GL031236, 2007.

Huang, Z., Li, H., Zheng, Y., and Peng, Y.: The lithosphere of North China Craton from surface wave tomography, Earth Planet. Sc. Lett., 288, 164-173, doi:10.1016/j.epsl.2009.09.019, 2009.

Huang, Z., Wang, L., Zhao, D., Mi, N., and Xu, M.: Seismic anisotropy and mantle dynamics beneath China, Earth Planet. Sc. Lett., 306, 105-117, doi:10.1016/j.eps1.2011.03.038, 2011.

Huang, Z.-M., Zhang, Y.-Z., Kotaki, M., and Ramakrishna, S.: A review on polymer nanofibers by electrospinning and their applications in nanocomposites, Compos. Sci. Technol., 63, 2223-2253, doi:10.1016/S0266-3538(03)00178-7, 2003.

Hung, S.-H., Chen, W.-P., Chiao, L.-Y., and Tseng, T.-L.: First multi-scale, finite-frequency tomography illuminates 3-D anatomy of the Tibetan plateau, Geophys. Res. Lett., 37, L06304, doi:10.1029/2009GL041875, 2010.

Jagoutz, O., Royden, L., Holt, A. F., and Becker, T. W.: Anomalously fast convergence of India and Eurasia caused by double subduction, Nat. Geosci., 8, 475-478, doi:10.1038/ngeo2418, 2015.

Jordan, T. and Watts, A.: Gravity anomalies, flexure and the elastic thickness structure of the India-Eurasia collisional system, Earth Planet. Sc. Lett., 236, 732-750, doi:10.1016/j.eps1.2005.05.036, 2005.

Karato, S.-I.: Grain-size distribution and rheology of the upper mantle, Tectonophys, 104, 155-176, doi:10.1016/00401951(84)90108-2, 1984.

Karato, S.-I.: Seismic anisotropy due to lattice preferred orientation of minerals: Kinematic or dynamic?, Geoph. Monog. Series, 39, 455-471, doi:10.1029/GM039p0455, 1987.
Karato, S.-I. and Wu, P.: Rheology of the Upper Mantle: A Synthesis, Science, 260, 771-778, doi:10.1126/science.260.5109.771, 1993.

Karplus, M., Zhao, W., Klemperer, S., Wu, Z., Mechie, J., Shi, D., Brown, L., and Chen, C.: Injection of Tibetan crust beneath the south Qaidam Basin: Evidence from INDEPTH IV wide-angle seismic data, J. Geophys. Res., 116, B07301, doi:10.1029/2010JB007911, 2011.

Kennett, B. L. N. and Engdahl, E.: Traveltimes for global earthquake location and phase identification, Geophys. J. Int., 105, 429-465, doi:10.1111/j.1365-246X.1991.tb06724.x, 1991.

Kreemer, C., Holt, W. E., and Haines, A. J.: An integrated global model of present-day plate motions and plate boundary deformation, Geophys. J. Int., 154, 8-34, doi:10.1046/j.1365246X.2003.01917.x, 2003.

Kumar, M. R. and Singh, A.: Evidence for plate motion related strain in the Indian shield from shear wave splitting measurements, J. Geophys. Res., 113, B08306, doi:10.1029/2007JB005128, 2008.

Kumar, P., Yuan, X., Kind, R., and Ni, J.: Imaging the colliding Indian and Asian lithospheric plates beneath Tibet, J. Geophys. Res., 111, B06308, doi:10.1029/2005JB003930, 2006.

Lavé, J., Avouac, J., Lacassin, R., Tapponnier, P., and Montagner, J.: Seismic anisotropy beneath Tibet: evidence for eastward extrusion of the Tibetan lithosphere?, Earth Planet. Sc. Lett., 140, 83-96, doi:10.1016/0012-821X(96)00045-3, 1996.

León Soto, G., Sandvol, E., Ni, J. F., Flesch, L., Hearn, T. M., Tilmann, F., Chen, J., and Brown, L. D.: Significant and vertically coherent seismic anisotropy beneath eastern Tibet, J. Geophys. Res., 117, B05308, doi:10.1029/2011JB008919, 2012.

Lev, E., Long, M. D., and van der Hilst, R. D.: Seismic anisotropy in Eastern Tibet from shear wave splitting reveals changes in lithospheric deformation, Earth Planet. Sc. Lett., 251, 293-304, doi:10.1016/j.eps1.2006.09.018, 2006.

Li, C., Van der Hilst, R. D., Meltzer, A. S., and Engdahl, E. R.: Subduction of the Indian lithosphere beneath the Tibetan Plateau and Burma, Earth Planet. Sc. Lett., 274, 157-168, doi:10.1016/j.eps1.2008.07.016, 2008.

Li, Y. H., Wu, Q. J., and Tian, X. B.: Crustal structure in the Yunnan region determined by modeling receiver functions, Chinese J. Geophys., 52, 67-80, 2009.

Lithgow-Bertelloni, C. and Richards, M. A.: The dynamics of Cenozoic and Mesozoic plate motions, Rev. Geophys., 36, $27-$ 78, doi:10.1029/97RG02282, 1998.

Long, M. D. and Silver, P. G.: Shear wave splitting and mantle anisotropy: measurements, interpretations, and new directions, Surv. Geophys., 30, 407-461, doi:10.1007/s10712-009-9075-1, 2009.

Mainprice, D., Barruol, G., and Ismail, W. B.: The seismic anisotropy of the Earth's mantle: from single crystal to polycrystal, Earth's Deep Interior: Mineral physics and tomography from the atomic to the global scale, edited by: Karato, S.I., Forte, A., Liebermann, R., Masters, G., and Stixrude, L., American Geophysical Union, Washington, D. C., 237-264, doi:10.1029/GM117p0237, 2000.

McKenzie, D. and Priestley, K.: The influence of lithospheric thickness variations on continental evolution, Lithos, 102, 1-11, doi:10.1016/j.lithos.2007.05.005, 2008. 
McNamara, D. E., Owens, T. J., Silver, P. G., and Wu, F. T.: Shear wave anisotropy beneath the Tibetan Plateau, J. Geophys. Res., 99, 13655-13665, doi:10.1029/93JB03406, 1994.

Molnar, P. and Tapponnier, P.: Cenozoic tectonics of Asia: effects of a continental collision, Science, 189, 419-426, doi:10.1126/science.189.4201.419, 1975.

Nelson, K. D., Zhao, W., Brown, L., Kuo, J., Che, J., Liu, X., Klemperer, S., Makovsky, Y., Meissner, R., Mechie, J., Kind, R., Wenzel, F., Nabelek, N. J., Leshou, C., Tan, H., Wei, W., Jones, A. G., Booker, J., Unsworth, M., Kidd, W. S. F., Hauck, M., Alsdorf, D., Ross, A., Cogan, M., Wu, C., Sandvol, E., and Edwards, M.: Partially molten middle crust beneath southern Tibet: synthesis of project INDEPTH results, Science, 274, 1684-1688, doi:10.1126/science.274.5293.1684, 1996.

Nicolas, A. and Christensen, N. I.: Formation of Anisotropy in Upper Mantle Peridotites-A Review, Composition, structure and dynamics of the lithosphere-asthenosphere system, edited by: Fuchs, K. and Froidevaux, C., American Geophysical Union, Washington, D. C., 111-123, doi:10.1029/GD016p0111, 1987.

Ozacar, A. A. and Zandt, G.: Crustal seismic anisotropy in central Tibet: Implications for deformational style and flow in the crust, Geophys. Res. Lett., 31, L23601, doi:10.1029/2004GL021096, 2004.

Pandey, S., Yuan, X., Debayle, E., Priestley, K., Kind, R., Tilmann, F., and Li, X.: A 3-D shear-wave velocity model of the upper mantle beneath China and the surrounding areas, Tectonophys, 633, 193-210, doi:10.1016/j.tecto.2014.07.011, 2014.

Plomerová, J., Babuška, V., Kozlovskaya, E., Vecsey, L., and Hyvönen, L.: Seismic anisotropy - a key to resolve fabrics of mantle lithosphere of Fennoscandia, Tectonophys, 462, 125-136, doi:10.1016/j.tecto.2008.03.018, 2008.

Priestley, K., Debayle, E., McKenzie, D., and Pilidou, S.: Upper mantle structure of eastern Asia from multimode surface waveform tomography, J. Geophys. Res., 111, B10304, doi:10.1029/2005JB004082, 2006.

Replumaz, A. and Tapponnier, P.: Reconstruction of the deformed collision zone between India and Asia by backward motion of lithospheric blocks, J. Geophys. Res., 108, 2285, doi:10.1029/2001JB000661, 2003.

Richardson, R.: Ridge forces, absolute plate motions, and the intraplate stress field, J. Geophys. Res., 97, 11739-11748, doi:10.1029/91JB00475, 1992.

Rowley, D. B. and Currie, B. S.: Palaeo-altimetry of the late Eocene to Miocene Lunpola basin, central Tibet, Nature, 439, 677-681, doi:10.1038/nature04506, 2006.

Royden, L. H., Burchfiel, B. C., King, R. W., Wang, E., Chen, Z., Shen, F., and Liu, Y.: Surface deformation and lower crustal flow in eastern Tibet, Science, 276, 788-790, doi:10.1126/science.276.5313.788, 1997.

Royden, L. H., Burchfiel, B. C., and van der Hilst, R. D.: The geological evolution of the Tibetan Plateau, Science, 321, 10541058, doi:10.1126/science.1155371, 2008.

Saikia, D., Ravi Kumar, M., Singh, A., Mohan, G., and Dattatrayam, R. S.: Seismic anisotropy beneath the Indian continent from splitting of direct $S$ waves, J. Geophys. Res., 115, B12315, doi:10.1029/2009JB007009, 2010.

Saltzer, R. L., Gaherty, J. B., and Jordan, T. H.: How are vertical shear wave splitting measurements affected by variations in the orientation of azimuthal anisotropy with depth?, Geophys. J. Int., 141, 374-390, doi:10.1046/j.1365-246X.2000.00088.x, 2000.

Sandvol, E., Ni, J., Kind, R., and Zhao, W.: Seismic anisotropy beneath the southern Himalayas-Tibet collision zone, J. Geophys. Res., 102, 17813-17823, doi:10.1029/97JB01424, 1997.

Sandvol, E. A., Ni, J. F., Hearn, T. M., and Roecker, S.: Seismic azimuthal anisotropy beneath the Pakistan Himalayas, Geophys. Res. Lett., 21, 1635-1638, doi:10.1029/94GL01386, 1994.

Sato, H., Fehler, M. C., and Maeda, T.: Seismic wave propagation and scattering in the heterogeneous earth, Springer, 496, doi:10.1007/978-3-540-89623-4, 2012.

Savage, M. K.: Seismic anisotropy and mantle deformation: What have we learned from shear wave splitting?, Rev. Geophys., 37, 65-106, doi:10.1029/98RG02075, 1999.

Schulte-Pelkum, V., Monsalve, G., Sheehan, A., Pandey, M. R., Sapkota, S., Bilham, R., and Wu, F.: Imaging the Indian subcontinent beneath the Himalaya, Nature, 435, 1222-1225, doi:10.1038/nature03678, 2005.

Shen, F., Royden, L. H., and Burchfiel, B. C.: Large-scale crustal deformation of the Tibetan Plateau, J. Geophys. Res., 106, 67936816, doi:10.1029/2000JB900389, 2001.

Shen, Z.-K., Lü, J., Wang, M., and Bürgmann, R.: Contemporary crustal deformation around the southeast borderland of the Tibetan Plateau, J. Geophys. Res., 110, B11409, doi:10.1029/2004JB003421, 2005.

Sherrington, H. F., Zandt, G., and Frederiksen, A.: Crustal fabric in the Tibetan Plateau based on waveform inversions for seismic anisotropy parameters, J. Geophys. Res., 109, B02312, doi:10.1029/2002JB002345, 2004.

Silver, P. G. and Chan, W. W.: Shear wave splitting and subcontinental mantle deformation, J. Geophys. Res., 96, 16429-16454, doi:10.1029/91JB00899, 1991.

Silver, P. G. and Savage, M. K.: The interpretation of shearwave splitting parameters in the presence of two anisotropic layers, Geophys. J. Int., 119, 949-963, doi:10.1111/j.1365246X.1994.tb04027.x, 1994.

Singh, A., Kumar, M. R., Raju, P. S., and Ramesh, D. S.: Shear wave anisotropy of the northeast Indian lithosphere, Geophys. Res. Lett., 33, doi:10.1029/2006GL026106, 2006.

Singh, A., Kumar, M. R., and Raju, P. S.: Mantle deformation in Sikkim and adjoining Himalaya: Evidences for a complex flow pattern, Phys. Earth Planet. In., 164, 232-241, doi:10.1016/00319201(93)90156-4, 2007.

Singh, A., Kumar, M. R., and Raju, P. S.: Seismic structure of the underthrusting Indian crust in Sikkim Himalaya, Tectonics, 29, doi:10.1029/2010TC002722, 2010.

Singh, A., Mercier, J.-P., Ravi Kumar, M., Srinagesh, D., and Chadha, R. K.: Continental scale body wave tomography of India: Evidence for attrition and preservation of lithospheric roots, Geochem. Geophy. Geosy., 15, 658-675, doi:10.1002/2013GC005056, 2014.

Singh, A., Singh, C., and Kennett, B.: A review of crust and upper mantle structure beneath the Indian subcontinent, Tectonophys, 644, 1-21, doi:10.1016/j.tecto.2015.01.007, 2015.

Singh, A., Eken, T., Mohanty, D. D., Saikia, D., Singh, C., and Kumar, M. R.: Significant seismic anisotropy beneath southern Tibet inferred from splitting of direct $S$ waves, Phys. Earth Planet. In., 250, 1-11, doi:10.1016/j.pepi.2015.11.001, 2016. 
Sol, S., Meltzer, A., Bürgmann, R., Van der Hilst, R., King, R., Chen, Z., Koons, P., Lev, E., Liu, Y., Zeitler, P., Zhang, X., Zhang, J., and Zurek, B.: Geodynamics of the southeastern Tibetan Plateau from seismic anisotropy and geodesy, Geology, 35, 563-566, doi:10.1130/G23408A.1, 2007.

Tapponnier, P., Peltzer, G., Le Dain, A., Armijo, R., and Cobbold, P.: Propagating extrusion tectonics in Asia: New insights from simple experiments with plasticine, Geology, 10, 611616, doi:10.1130/0091-7613(1982)10<611:PETIAN>2.0.CO;2, 1982.

Tapponnier, P., Zhiqin, X., Roger, F., Meyer, B., Arnaud, N., Wittlinger, G., and Jingsui, Y.: Oblique stepwise rise and growth of the Tibet Plateau, Science, 294, 1671-1677, doi:10.1126/science.105978, 2001.

Tseng, T.-L., Chen, W.-P., and Nowack, R. L.: Northward thinning of Tibetan crust revealed by virtual seismic profiles, Geophys. Res. Lett., 36, L24304, doi:10.1029/2009GL040457, 124304, 2009.

Van Hinsbergen, D. J., Lippert, P. C., Dupont-Nivet, G., McQuarrie, N., Doubrovine, P. V., Spakman, W., and Torsvik, T. H.: Greater India Basin hypothesis and a two-stage Cenozoic collision between India and Asia, P. Natl. Acad. Sci. USA, 109, 7659-7664, doi:10.1073/pnas.1117262109, 2012.

Vinnik, L. and Montagner, J.-P.: Shear wave splitting in the mantle Ps phases, Geophys. Res. Lett., 23, 2449-2452, doi:10.1029/96GL02263, 1996.

Vinnik, L., Green, R., and Nicolaysen, L.: Recent deformations of the deep continental root beneath southern Africa, Nature, 375, 50-52, doi:10.1038/375050a0, 1995.

Vinnik, L., Singh, A., Kiselev, S., and Kumar, M. R.: Upper mantle beneath foothills of the western Himalaya: subducted lithospheric slab or a keel of the Indian shield?, Geophys. J. Int., 171, 1162-1171, doi:10.1111/j.1365-246X.2007.03577.x, 2007.

Vinnik, L. P., Makeyeva, L. I., Milev, A., and Usenko, A. Y.: Global patterns of azimuthal anisotropy and deformations in the continental mantle, Geophys. J. Int., 111, 433-447, doi:10.1111/j.1365-246X.1992.tb02102.x, 1992.

Walsh, B. M., Sibeck, D. G., Nishimura, Y., and Angelopoulos, V.: Statistical analysis of the plasmaspheric plume at the magnetopause, J. Geophys. Res., 118, 4844-4851, doi:10.1002/jgra.50458, 2013.

Wang, C., Chang, L., Lü, Z., Qin, J., Su, W., Silver, P., and Flesch, L.: Seismic anisotropy of upper mantle in eastern Tibetan Plateau and related crust-mantle coupling pattern, Sci. China Ser. D, 50, 1150-1160, doi:10.1007/s11430-007-0053-5, 2007.
Wang, C.-Y., Flesch, L. M., Silver, P. G., Chang, L.-J., and Chan, W. W.: Evidence for mechanically coupled lithosphere in central Asia and resulting implications, Geology, 36, 363-366, doi:10.1130/G24450A.1, 2008.

Wüstefeld, A. and Bokelmann, G.: Null detection in shear-wave splitting measurements, B. Seismol. Soc. Am., 97, 1204-1211, doi:10.1785/0120060190, 2007.

Wüstefeld, A., Bokelmann, G., Zaroli, C., and Barruol, G.: SplitLab: A shear-wave splitting environment in Matlab, Comput. Geosci., 34, 515-528, doi:10.1016/j.cageo.2007.08.002, 2008.

Yao, H., Beghein, C., and Van Der Hilst, R. D.: Surface wave array tomography in SE Tibet from ambient seismic noise and twostation analysis-II, Crustal and upper-mantle structure, Geophys. J. Int., 173, 205-219, doi:10.1111/j.1365-246X.2007.03696.x, 2008.

Yao, H., Van Der Hilst, R. D., and Montagner, J.-P.: Heterogeneity and anisotropy of the lithosphere of SE Tibet from surface wave array tomography, J. Geophys. Res., 115, B12307, doi:10.1029/2009JB007142, 2010.

Yin, A. and Harrison, T. M.: Geologic Evolution of the HimalayanTibetan Orogen, Annu. Rev. Earth Planet Sci., 28, 211-280, doi:10.1146/annurev.earth.28.1.211, 2000.

Zhang, P.-Z., Shen, Z., Wang, M., Gan, W., Bürgmann, R., Molnar, P., Wang, Q., Niu, Z., Sun, J., Wu, J., Hanrong, S., and Xinzhao, Y.: Continuous deformation of the Tibetan Plateau from global positioning system data, Geology, 32, 809-812, doi:10.1130/G20554.1, 2004.

Zhao, J., Yuan, X., Liu, H., Kumar, P., Pei, S., Kind, R., Zhang, Z., Teng, J., Ding, L., Gao, X., Xu, Q., and Wang, W.: The boundary between the Indian and Asian tectonic plates below Tibet, P. Natl. Acad. Sci. USA, 107, 11229-11233, doi:10.1073/pnas.1001921107, 2010.

Zhao, J., Murodov, D., Huang, Y., Sun, Y., Pei, S., Liu, H., Zhang, H., Fu, Y., Wang, W., Cheng, H., and Tang, W.: Upper mantle deformation beneath central-southern Tibet revealed by shear wave splitting measurements, Tectonophys, 627, 135-140, doi:10.1016/j.tecto.2013.11.003, 2014.

Zhou, H. and Murphy, M. A.: Tomographic evidence for wholesale underthrusting of India beneath the entire Tibetan plateau, J. Asian Earth Sci., 25, 445-457, doi:10.1016/j.jseaes.2004.04.007, 2005. 